\title{
Etiology and Treatment of the Psychological Side Effects Associated With Cancer Chemotherapy: A Critical Review and Discussion
}

\author{
Michael P. Carey \\ Syracuse University
}

\author{
Thomas G. Burish \\ Vanderbilt University
}

\begin{abstract}
Cancer patients receiving chemotherapeutic treatments routinely experience a wide range of distressing side effects, including nausea, vomiting, and dysphoria. Such symptoms often compromise patients' quality of life and may lead to the decision to postpone or even reject future, potentially life-saving, treatments. In this article, we discuss the hypotheses that have been offered to explain the development of such symptoms. We also review, in greater detail, the research evidence for the efficacy of five treatments for such symptoms: hypnosis, progressive muscle relaxation training with guided imagery, systematic desensitization, attentional diversion or redirection, and biofeedback. We discuss the implications of this treatment research, paying particular attention to factors associated with treatment outcome, mechanisms of treatment effectiveness, and issues associated with clinical application.
\end{abstract}

Chemotherapy is the treatment of choice for hundreds of thousands of cancer patients diagnosed each year in the United States (Silverberg \& Lubera, 1986). Its frequent use with cancer patients is the result of recent advances in antineoplastic medication; new and more effective medications have increased the life expectancy for many patients and, in some cases, have resulted in remission and cure. Unfortunately, such long-term gain can come at considerable short-term cost to the cancer patient in the form of aversive and debilitating side effects. Among the more common drug-induced side effects are alopecia, stomatitis, immunosuppression, anorexia, nausea, and vomiting. In addition to these pharmacological side effects, chemotherapy patients also experience psychological side effects.

Psychological side effects, which should not necessarily be regarded as abnormal or indicative of psychopathology, are those that cannot be attributed directly to the antineoplastic medications; instead, such symptoms are believed to result from psychological processes (e.g., learning) that occur in the chemotherapy context. These symptoms can occur before chemotherapy (in which case they are referred to as anticipatory side effects) as well as during and after the actual chemotherapy infusion. When they occur after chemotherapy has been administered (and while the drugs remain pharmacologically active within the system), it is practically impossible to distinguish

We wish to thank Kate B. Carey and the anonymous reviewers for their many helpful suggestions on an earlier draft of this review. The writing of this manuscript was supported in part by Grant No. 25516 from the National Cancer Institute, Grant No. PBR-29 from the American Cancer Society, and Grant No. 24 from Syracuse University.

Correspondence concerning this article should be addressed to Michael P. Carey, Department of Psychology, 430 Huntington Hall, Syracuse University, Syracuse, New York 13244; or to Thomas G. Burish, 221 Kirkland Hall, Vanderbilt University, Nashville, Tennessee 37240. such psychological side effects from their pharmacological counterparts. Unfortunately, there has been much inconsistency in the literature concerning the definition of these symptoms and the terminology used to describe them. For the most part, however, research with humans has focused on three symptoms, namely, nausea, vomiting, and dysphoria. However, it should be noted that considerable animal research and recent human research have also focused on other side effects of cancer treatments, especially learned side effects such as conditioned taste and food aversions (e.g., Bernstein \& Borson, 1986; Smith, Blumsack, \& Bilek, 1985) and conditioned immunosuppression (e.g., Ader, 1981; Ader \& Cohen, 1985). These phenomena may develop through mechanisms that are similar to those that are the focus of this article.

Symptoms such as nausea, vomiting, and dysphoria are not only frequent among cancer chemotherapy patients but can also be extremely stressful. In addition to the physical and affective distress they cause, many patients are embarrassed by their display of symptoms (e.g., anticipatory vomiting), and others even fear for their sanity. In fact, some patients eventually discontinue chemotherapy, abandoning the hope for remission and cure rather than suffer from such symptoms (Wilcox, Fetting, Nettesheim, \& Abeloff, 1982). It has been suggested that still other patients will turn to ineffective and expensive "quack" treatments rather than tolerate the paradoxical worsening quality of life that chemotherapy can bring. Consequently, oncologists (e.g., Laszlo \& Lucas, 1981), oncology nurses (e.g., Oberst, 1978), and cancer patients themselves (e.g., Cohn, 1982) have all implored researchers to identify an effective treatment for the side effects associated with cancer chemotherapy.

Pharmacological agents (e.g., prochlorperazine, delta-9-tetrahydrocannabinol) have been used to control the psychological responses to chemotherapy, but standard antiemetics have been found largely ineffective for this type of symptom (Laszlo, 1983; 
Morrow, Arseneau, Asbury, Bennett, \& Boros, 1982). In addition, there is evidence that these medications can actually worsen the symptomatology under some conditions (Zeltzer, LeBaron, \& Zeltzer, 1984a). Moreover, even when antiemetics provide some relief, they often have side effects of their own (e.g., sedation, dystonic reactions) or administration demands (e.g., the need for inpatient hospitalization) that limit their acceptance or usefulness among some patients. The ineffectiveness, the paradoxical worsening of symptoms, and the practical limitations of pharmacological agents have all prompted researchers to consider psychological treatments as an alternative method of controlling such symptoms.

In recent years, research on the etiology and treatment of anticipatory and exacerbatory side effects of cancer chemotherapy has burgeoned and has attracted researchers from several health-care disciplines. This increasingly widespread interest is based on at least two primary factors. First, from a theoretical point of view, the psychological side effects of cancer chemotherapy present an unusual opportunity to study the natural development of reactions to repeated aversive treatment within a clinical population. As we shall see, these reactions share some commonalities with other aversive responses but also appear to have some notable differences. Second, from a clinical point of view, these side effects are quite prevalent and can be aversive and debilitating. As a result, they represent an important clinical problem.

The primary purpose of this article is to review the research evidence on the etiology and treatment of the most common psychological side effects associated with cancer chemotherapy, namely, nausea, vomiting, and dysphoria. We begin with an overview and evaluation of the etiological formulations that have been proffered to explain the development of such symptoms. After this discussion of etiology, we review and critique the treatment literature, focusing on investigations that provide quantitative outcome data. We discuss the implications of this research, paying particular attention to patient factors associated with outcome, hypothesized mechanisms by which the treatments may exert their impact, and clinical issues in the application of such interventions.

\section{Etiology of Psychological Side Effects Associated With Cancer Chemotherapy}

Psychological side effects are believed to be relatively common. For example, prevalence data obtained from prospective, longitudinal studies indicate that approximately $45 \%$ of adult cancer patients experience nausea, vomiting, or both in the 24 hr preceding their chemotherapy (Burish \& Carey, 1986). Although precise estimates of the prevalence of postchemotherapy psychological side effects in adults are not available, they are believed to be even more common (Burish \& Carey, 1986).

Several causal explanations have been offered to explain the development of psychological side effects. One hypothesis is that these symptoms "may be surfacing manifestations of underlying psychological readjustment problems, associated with lifethreatening illness" (Chang, 1981, p. 707). This view suggests that nonpharmacological symptoms represent the negative affect that patients harbor toward their chemotherapy treat- ments. To date, no data are available to support this assertion. A second hypothesis is that patients may display such symptoms in order to gain attention and sympathy. Inconsistent with this hypothesis, however, is the observation that the punishing side effects of chemotherapy far outweigh any secondary gains that may be realized by cancer patients; moreover, there are no data to support the notion that removal of attention can reduce nonpharmacological symptoms. A third hypothesis is that the observed symptoms may "be produced by brain metastasis or local cancer involvement of the gastrointestinal tract" (Chang, 1981, p. 707). Although this explanation may be accurate for a few patients, it has been ruled out as an explanation for most patients (e.g., Morrow, 1982).

In contrast with the first three hypotheses, which are speculative and lack empirical support, the fourth hypothesis has been supported by the research literature. This hypothesis holds that nonpharmacological or psychological side effects develop through an associative learning process. According to the most widely accepted conditioning viewpoint, after one or more pairings, an association is established between the pharmacological side effects (the unconditioned responses; UCRs) caused by the chemotherapy (the unconditioned stimulus; UCS) and various stimuli (e.g., sights, smells, thoughts; the conditioned stimuli; CSs) associated with the chemotherapy setting. As a result of repeated associations, the CSs begin to elicit nausea, vomiting, and dysphoria (the conditioned responses; CRs), even in the absence of the UCS. Two variations of the conditioning model have also been suggested. The first, proposed by Leventhal, Easterling, Nerenz, and Love (1988), is that postchemotherapy nausea and vomiting might occasionally serve as the UCS, with responses to this nausea and vomiting (e.g., anxiety and secondary nausea occurring later in time) being the UCRs. These UCRs then become conditioned to various stimuli in the chemotherapy environment and thereby take the form of CRs. Thus, in this first variation of the conditioning model, the morphology of the CS and CR is similar to that of the original model, but the UCS and UCR are not. The second variation was suggested by Garcia y Robertson and Garcia (1985), who believe that conditioned responses to cancer chemotherapy may develop through a process that closely resembles taste aversion learning. Although the published literature on conditioned responses to cancer chemotherapy has been based almost exclusively on the first model of conditioning, it should be noted that these two variations do provide viable conceptualizations of alternative, though not necessarily mutually exclusive, processes.

There are several sources of data that converge to support the hypothesis that associative learning is the primary phenomenon underlying the etiology of psychological symptoms. In no case were the data generated by experimental research that was designed deliberately to induce conditioned nausea and vomiting in cancer chemotherapy patients through controlled experimental manipulations, a procedure that would be ethically unacceptable. Rather, the data are based on analogous phenomena or experimental outcomes that consistently, logically, or exclusively point to associative learning as the most reasonable explanation. At least four sources of supporting data can be identified.

First, the symptoms that are displayed by chemotherapy pa- 
tients have several topographical similarities to those of laboratory animals that ingest a gastrotoxic substance or that are irradiated while eating a certain food. The animals subsequently avoid that substance or food during future feedings, a phenomenon referred to as learned taste aversion (for an extended discussion of the similarities of conditioned nausea and vomiting in cancer patients and learned taste aversions, see Garcia y Robertson \& Garcia, 1985). The symptoms have been shown to result from a learning process that is associative in nature, although it deviates, as does the conditioned response of chemotherapy patients, from the traditional classical conditioning paradigm in some interesting respects (e.g., the symptoms often develop after only one or a few associations and despite the fact that there may be several hours between the UCS and UCR). Another example of documented animal conditioning that bears even closer resemblance to the chemotherapy situation was demonstrated by Collins and Tatum (1925) and Pavlov (1927). These investigators showed that dogs repeatedly injected with an emetic drug developed conditioned vomiting in response to stimuli associated with the injection.

Second, several human studies provide data that support an associative learning explanation. For example, I. L. Bernstein and her colleagues (e.g., I. L. Bernstein, 1978; I. L. Bernstein \& Webster, 1980) demonstrated experimentally that taste aversions can develop in chemotherapy patients as a result of the emetic properties of the infused drugs. For example, in one study the investigators assigned pediatric cancer patients receiving emetogenic chemotherapy agents to one of two groups: to an experimental group that received a novel-flavored ice cream shortly before their scheduled drug treatment or to a control group that did not receive the ice cream. A second control group of patients receiving nonemetic chemotherapy drugs was also included. After 2 or more weeks, patients in all groups were offered either some of the novel-flavored ice cream or an opportunity to play with a game. Patients in the two control groups overwhelmingly chose the ice cream; patients in the experimental group showed an aversion to the ice cream, generally preferring the game. Similar results were subsequently demonstrated in adult cancer patients (see I. L. Bernstein \& Webster, 1985, for a review).

Third, there have been reports of cancer chemotherapy patients becoming conditioned to antiemetic treatments. In these situations, the antiemetic was apparently given each time the patient became nauseated or was vomiting; as a result, it became associated with nausea and vomiting and later was able to elicit, on its own, nausea and vomiting. For example, Kutz, Borysenko, Come, and Benson (1980) reported the case of a patient with neurofibrosarcoma who smoked marijuana to alleviate severe nausea and vomiting. After chemotherapy was discontinued, the smell of marijuana in social situations elicited nausea and vomiting. In another case reported by the same authors, the marijuana was administered in brownies and cookies. For a year after the chemotherapy was discontinued, the taste or sight of these foods produced nausea. Similar conditioning to antiemetics has been reported by other investigators (e.g., Morrow et al., 1982).

Fourth, research has shown that factors related to the development of conditioned symptoms in cancer chemotherapy pa- tients conform to the principles of associative learning. For example, Andrykowski et al. (in press) and Andrykowski, Redd, and Hatfield (1985) conducted two longitudinal studies of the development of anticipatory nausea in cancer chemotherapy patients. In these investigations, which together involved the study of over 150 patients, the authors found that anticipatory nausea never occurred without the prior occurrence of postchemotherapy nausea, that is, consistent with the principles of associative learning, the presence of a UCR was necessary for the acquisition of a CR. Moreover, after a careful analysis of other factors that contributed to the development of anticipatory symptoms, the authors concluded that, consistent with an associative learning model, "all of the factors that reliably predicted the development of AN [anticipatory nausea] were either directly or indirectly linked to the magnitude" of the unconditioned symptoms (Andrykowski et al., in press, p. 11). As has been noted elsewhere (Burish \& Carey, 1986), other descriptive data on the development and nature of conditioned responses in cancer chemotherapy patients also consistently conform, in prospective as well as retrospective studies, to the principles of associative learning.

In addition to supporting the conditioning model, the available data suggest that several factors can serve to mediate or potentiate the learning process and thereby produce considerable variation in symptom development. These individual difference factors may arise independently of, but nonetheless contribute to, the development of conditioned responses.

One major individual difference may be proneness to nausea and vomiting. Research has suggested that patients who have a history of motion sickness or of experiencing nausea and vomiting to various foods or situations (e.g., pregnancy) are more likely to report posttreatment and anticipatory nausea and vomiting in response to cancer chemotherapy (Jacobsen et al., 1988; Morrow, 1985). Morrow (1985) has suggested that there is a neurological basis for this relationship. The experience of nausea and vomiting is thought to result from activation of the "vomiting center," located in the lateral reticular formation of the medulla oblongata (Borison \& McCarthy, 1983). The vomiting center has four major inputs, including one from the vestibular system, which is thought to play a role in motion sickness. It has been suggested that in addition to affecting the other major inputs, chemotherapy may affect the vestibular system, which in patients with a susceptibility to motion sickness may lead to additional stimulation of the vomiting center and therefore an increased likelihood of nausea and vomiting (Morrow, 1985). Redd and his colleagues (Jacobsen et al., 1988; Andrykowski et al., in press) have suggested that there may be constitutional differences in cancer patients' susceptibility to gastrointestinal distress, including that due to chemotherapy. Patients with a greater constitutional vulnerability to gastrointestinal distress may be more likely to respond to chemotherapy with high levels of posttreatment nausea and vomiting, which in turn increases the likelihood that they will develop conditioned nausea and vomiting, in comparison with patients without this diathesis. In summary, the data suggest that patients with a past history of nausea and vomiting resulting from motion sickness, certain foods, or other experiences are more likely to develop 
conditioned nausea and vomiting in response to cancer chemotherapy.

A second major factor that appears to affect the development of conditioned responses to chemotherapy is a patient's anxiety level. ${ }^{1}$ Specifically, state anxiety levels have been positively related to the presence of conditioned responses in a number of retrospective studies (e.g., Ingle, Burish, \& Wallston, 1984; van Komen \& Redd, 1985) and prospective investigations (e.g., Andrykowski et al., 1985, in press; Nerenz, Leventhal, Easterling, \& Love, 1986). For example, Nerenz et al. (1986) interviewed cancer patients before each of their first six treatment cycles. The authors found that the incidence of anticipatory nausea was related to the level of pretreatment anxiety: for mildly anxious patients the incidence averaged $9.8 \%$; for highly anxious patients the incidence was approximately twice as much, averaging $18.1 \%$. Andrykowski et al. (1985) found that a patient's self-reported anxiety level before treatments accounted for more variance $(13.6 \%)$ than any other single variable except posttreatment nausea in determining whether a patient developed anticipatory nausea.

Although data from numerous studies appear to suggest that heightened anxiety levels facilitate the development of conditioned symptoms, two questions remain. First, what are the temporal parameters that determine the relationship between state anxiety and the development of conditioned responses? That is, exactly when during the course of chemotherapy do elevated anxiety levels produce this relationship? Second, why is heightened anxiety associated with conditioned symptoms? A number of possible answers have been discussed, although none have been tested in the chemotherapy context. In most cases, investigators have speculated that anxiety directly or indirectly affects the associative learning process in ways that lead to enhanced conditioning. For example, some of the explanations suggest that anxiety levels directly affect conditioning by influencing the speed with which associative learning takes place. According to this explanation, highly anxious patients condition more quickly than do less anxious patients (e.g., Spence, 1958). Data recently reported by Andrykowski and Redd (1987) conflict with this explanation, however. These authors interviewed patients before each of their chemotherapy treatments to determine pretreatment anxiety levels and pre- and posttreatment nausea levels. They found that patients who developed anticipatory symptoms late in the course of chemotherapy (i.e., after their seventh treatment) generally had higher anxiety levels during all treatments than did patients who developed anticipatory symptoms early in the treatment course. Andrykowski and Redd (1987) also noted that late-onset patients generally had lower posttreatment nausea levels until the session just before they developed anticipatory nausea, at which time their posttreatment levels increased substantially. The authors speculated that the heightened pretreatment anxiety levels eventually led to the increased posttreatment nausea and that once posttreatment nausea increased, patients were more likely to develop anticipatory symptoms (i.e., the greater the intensity of the unconditioned response, the more likely the development of a conditioned response).

Others have focused on different parameters in trying to explain the relationship between anxiety and conditioning. Dol- gin, Katz, McGinty, and Siegel (1985), for example, have suggested that highly anxious patients tend to show high levels of vigilance to their environments and, as a result, tend to notice more closely various stimuli in the clinic setting. Such attention increases the likelihood that these stimuli will develop into CSs. They found that consistent with this hypothesis, pediatric cancer patients with anticipatory symptoms attended to and processed more stimuli in their environments, and habituated to these stimuli more slowly, than did matched patients without anticipatory symptoms.

Although most of the speculation about the relationship between anxiety and conditioned symptoms focuses on the role of anxiety within the learning paradigm, J. H. Fetting (personal communication, March 1,1988 ) has suggested a neurologically based explanation that involves the relationship between anxiety and neurotransmitter changes. In the first stage of a hypothesized two-stage process, a cancer patient's propensity for experiencing nausea and vomiting is increased as a result of either a decreased nausea/vomiting threshold or enhanced neuronal firings, either or both of which might be caused by repeated bouts of nausea and vomiting during periods of high anxiety. As a result of this enhanced propensity, a variety of stimuli will more readily cause gastrointestinal upset in the future.

In the second stage, increased noradrenergic activity, caused by the heightened anxiety or stress levels, contributes to the development of anticipatory nausea and vomiting in patients with the increased propensity. The process by which the increased noradrenergic activity leads to these effects is as yet undetermined, but J. H. Fetting (personal communication, March 1, 1988) speculated that with repeated exposure to emetogenic chemotherapy, the noradrenergic terminals in areas adjacent to the vomiting center in the cortex may show increased activity, leading to greater stimulation of the vomiting center. In an initial test of this hypothesis, Fetting et al. (1987) administered clonidine, a drug that reduces noradrenergic activity, to 8 chemotherapy patients who displayed anticipatory symptoms to their chemotherapy. After one trial of clonidine, the anticipatory symptoms were completely eliminated in $4(50 \%)$ of the patients. Postchemotherapy nausea and vomiting appeared to be unaffected.

Overall, then, it appears that the psychological symptoms that occur during cancer chemotherapy, particularly the nausea and vomiting that occur prior to drug infusion, are acquired through an associative learning process; moreover, the data suggest that the development of such symptoms is moderated by

\footnotetext{
${ }^{1}$ For the sake of completeness, it should be noted that in addition to anxiety level, a number of other individual difference factors have been found to be correlated with the presence of anticipatory symptoms, for example, experiencing taste sensations during chemotherapy, having an inhibitive rather than facilitative coping style, being treated in a large group room rather than in a small private room, being younger rather than older, experiencing itching sensations during chemotherapy, and receiving chemotherapy treatments through long infusions rather than through short push injections (see Burish \& Carey, 1986, for a review). However, most of these factors have been reported in retrospective investigations exclusively, have been found in only one or two studies and not in others, and have not been linked causally to the development of conditioned symptoms.
} 
one's prior experience with gastrointestinal upset from factors such as motion sickness or certain foods and by one's treatment-related anxiety level. Thus many writers have concluded that the psychological symptoms that occur in the chemotherapy setting are conditioned responses. In this regard, it is important to note that conditioned responses to cancer chemotherapy are similar, developmentally and phenomenologically, to conditioned aversive responses that develop routinely in other clinical contexts. For example, Garcia y Robertson and Garcia (1985) have related the animal and human literature on learned taste aversions to the research on conditioned nausea and vomiting in cancer chemotherapy patients. Conditioned responses to cancer chemotherapy can also be viewed as a subset of other conditioned drug responses (e.g., to morphine or alcohol; Siegel, 1979). Although the review of the extensive literature on conditioned aversive responses is beyond the scope of this article, it is important to keep these similarities in mind when reviewing the treatment literature because many of the procedures that have been used to ameliorate or prevent conditioned responses in cancer chemotherapy patients are similar to or are based on the same principles as those that have been used with other types of conditioned aversive responses. Many of the treatment advances that have been made in the cancer area are, therefore, potentially applicable to other areas as well.

Although associative learning appears to play an important role in the etiology of psychological side effects, we propose that side effects in the chemotherapy context might also result from, or be exacerbated by, a fifth mechanism, namely, psychological stress (i.e., the process that occurs when a person appraises a situation or stimulus as taxing his or her resources and endangering his or her well-being; Lazarus \& Folkman, 1984). Thus, we hypothesize that a person who appraises the chemotherapy process as threatening or who is unprepared to cope with its demands might experience negative outcomes (e.g., dysphoria, nausea). It is important to emphasize that by psychological stress we are referring broadly to the appraisal and coping process, not solely to an affective state that results from that process (e.g., increased anxiety). In addition to initiating symptoms, psychological stress can worsen already existing (i.e., pharmacological and conditioned) symptoms. Thus, stress can play a role at almost any stage in the development and expression of psychological symptoms to cancer chemotherapy. Support for the role of stress in psychological symptoms comes both from the general stress literature (e.g., Lazarus, 1966; Lazarus \& Folkman, 1984; Selye, 1976) and from empirical work conducted specifically in the chemotherapy context (e.g., Nerenz, Leventhal, \& Love, 1982; Nerenz, Leventhal, Love, \& Ringler, 1984). Unfortunately, most investigators have focused either on the role of associative learning or on the role of stress in accounting for the development of psychological symptoms, although there have been exceptions (e.g., Nerenz et al., 1982). In the end, however, we suspect that both processes are implicated, perhaps in a synergistic way.

In summary, five explanations have been put forward to explain the development of psychological symptoms in the chemotherapy context. Our review and interpretation of the literature leads us to conclude that many of these symptoms, especially those that occur prior to chemotherapy, are the result of associative learning. Furthermore, we have proposed that psychological stress may cause a variety of difficulties, or it may exacerbate existing symptoms. Thus we conclude that at least two factors contribute to the development and expression of psychological symptoms in the chemotherapy context: associative learning and psychological stress. Both can occur prior to, during, or after chemotherapy administration. It is likely that these two mechanisms co-occur with each other and perhaps with pharmacological factors to produce symptoms or symptom clusters. Next, we turn to an evaluation of interventions used to treat these side effects.

\section{Review of Research on the Treatment of Psychological Side Effects}

Five different psychological interventions have been investigated as techniques to ameliorate the conditioned and stressrelated side effects associated with cancer chemotherapy: hypnosis, progressive muscle relaxation training with guided imagery, systematic desensitization, biofeedback, and distraction. ${ }^{2}$ For each intervention, we provide a brief description of the technique and then review the research evaluating that technique. Although other techniques have been used clinically (e.g., stress inoculation training; see Moore \& Altmaier, 1981), we do not include such interventions in our review because they have not yet been subjected to controlled research.

\section{Hypnosis}

Hypnosis was probably the first psychological technique used to control the side effects associated with chemotherapy and is still the most widely used procedure with children and adolescents. Our review of this literature suggests that the term hypnosis does not describe a specific technique as much as it refers to a number of induction procedures that require that the patient be completely attentive and absorbed in an activity prescribed or directed by the therapist. This activity may be purely cognitive, or it may include both cognitive and behavioral components. Hypnotic induction procedures may involve psychological quiescence (i.e., relaxation) and augmented suggestibility (cf. Wadden \& Anderton, 1982), although these characteristics have not been reported universally in the cancer chemotherapy literature. For example, when used with children, hypnosis is usually characterized by a heavy reliance upon the use of playful fantasy rather than on the more passive images of natural beauty that are frequently used with adults; moreover, hypnotic imagery with children is often accompanied by physical movement and the use of toys and dolls, both of which may actually increase physiological arousal (Zeltzer \& LeBaron, 1986). In

\footnotetext{
${ }^{2}$ It is possible that the treatments reviewed decrease pharmacological side effects as well as conditioned and stress-related symptoms; however, it is practically impossible to separate out these differential effects when measuring postchemotherapy outcome measures. Many researchers who use psychological interventions have assumed, conservatively, that postchemotherapy symptom reductions resulting from these interventions reflect only the diminuation of psychologically produced symptoms.
} 
contrast, when used with adult patients, hypnosis typically involves an induction procedure that is designed to produce deep physiological relaxation (e.g., Redd, Andresen, \& Minagawa, 1982) and often employs imagery and suggestions related to natural beauty and serenity. Operationally, Redd (1985/1986) has noted that "the procedures for inducing passive relaxation are identical to those frequently used by many professionals who identify their procedures as hypnosis" (p. 21).

The early research on hypnosis with children (e.g., LaBaw, Holton, Tewell, \& Eccles, 1975), adolescents (e.g., Ellenberg, Kellerman, Dash, Higgins, \& Zeltzer, 1980), and adults (e.g., Dempster, Balson, \& Whalen, 1976) suggested that hypnosis could reduce nausea, vomiting, pain, and the negative emotions associated with chemotherapy. Though encouraging, this early research was more heuristically than empirically valuable because it did not report objective data, use statistical analyses, or employ adequate methodological controls.

The controlled work with hypnosis is summarized in Table 1; the most programmatic set of studies has been conducted by Zeltzer and her colleagues with pediatric patients. These studies have either used hypnosis patients as their own controls (LeBaron \& Zeltzer, 1984; Zeltzer, Kellerman, Ellenberg, \& Dash, 1983) or compared them to patients receiving supportive counseling (Zeltzer, LeBaron, \& Zeltzer, 1984b). Overall, this series of studies suggests that after one to three training sessions, patients receiving hypnosis reported reduced levels of postchemotherapy nausea and vomiting and that any postchemotherapy side effects that did remain were less bothersome than they were prior to training. Moreover, these benefits continued after training when the therapist was no longer present. No data on anticipatory symptoms were reported.

In the only hypnosis study to include a no-treatment control group, Cotanch, Hockenberry, and Herman (1985) compared 6 children given hypnosis plus standard antiemetic treatment with 6 children who received the standard antiemetic treatment alone. Results indicated that patients receiving hypnosis experienced reductions in the intensity and severity of both nausea and vomiting and an increase in food intake after chemotherapy, in comparison with patients receiving standard procedures.

Finally, in the only controlled study to use hypnosis with adults, Redd et al. (1982) studied 6 patients who had experienced anticipatory nausea and vomiting prior to at least their last three chemotherapy treatments. After completing two training sessions, the patients underwent chemotherapy while hypnotized. All 6 patients reported decreased nausea and were observed by nurses to have ceased all vomiting prior to and during the chemotherapy sessions in which hypnosis was used. When the patients did not use hypnosis during subsequent chemotherapy sessions, the anticipatory symptoms returned. No data on postchemotherapy symptoms were reported.

Overall, it appears that hypnotic procedures are an effective intervention for reducing both anticipatory and postchemotherapy nausea and vomiting and the negative affects associated with chemotherapy. Continued research is needed to replicate these findings, especially in adults. In this regard, it is important that investigators state explicitly which induction techniques and procedures they have used. Moreover, two points should be made regarding the use of hypnosis with cancer patients. First, not all patients will accept hypnosis (Hendler \& Redd, 1986; Redd \& Andrykowski, 1982; Zeltzer et al., 1983). Reasons for rejection typically have involved misperceptions about the process of hypnosis and potential posthypnotic effects. In an attempt to sidestep such concerns, Redd and his colleagues now refer to their hypnosis procedure as passive relaxation training with guided imagery, and they report greater acceptance by patients as a result of this change (W. H. Redd, personal communication, January 22, 1988). Second, in the only study that has compared hypnosis to an alternate treatment, it was found that adolescent patients who received hypnosis did not improve more than patients who received supportive counseling (Zeltzer et al., 1984b). Thus, although hypnosis may be effective, some people may not accept it, and others may be treated as effectively with alternate procedures.

\section{Progressive Muscle Relaxation Training With Guided Imagery}

Although hypnosis was probably the first psychological technique to be used in the chemotherapy context, progressive muscle relaxation training (PMRT) is the most widely researched technique. ${ }^{3}$ PMRT is based on a series of muscle tensing and relaxing exercises developed by Jacobson (1938) and later modified by D. A. Bernstein and Borkovec (1973), among others. This procedure is sometimes referred to as active relaxation training because it includes a muscle tensing component. Relaxation training procedures that do not include a tensing component have also been used in the chemotherapy context and are generally referred to as passive relaxation procedures. In the cancer chemotherapy context, PMRT has usually been supplemented with guided imagery during the infusion period; guided imagery involves the use of a sequence of thoughts and mental pictures to facilitate relaxation (see Turk, Meichenbaum, \& Genest, 1983, pp. 285-291, for examples of relaxation imagery). In most of the research reported in this area, the imagery is individualized to each patient on the basis of a preintervention interview.

As with hypnosis, uncontrolled case reports of the use of PMRT and guided imagery with cancer chemotherapy patients are available (e.g., Hamberger, 1982; Scott, Donahue, Mastrovito, \& Hakes, 1983). These reports provide little more than suggestive evidence for the efficacy of relaxation training and guided imagery. Fortunately, controlled research on PMRT and guided imagery has been ample and provides stronger data.

The controlled research on PMRT and guided imagery is summarized in Table 2; this research has been conducted almost exclusively with adults and has focused on the psychological side effects and distress that occur during and after chemotherapy injections. Burish and his colleagues have completed five studies on the effectiveness of PMRT and guided imagery.

\footnotetext{
${ }^{3}$ Relaxation is a broad term that has been used to refer to a disparate array of activities, including watching television, taking a cruise, and lying on a beach. These pleasurable activities may or may not result in physiological quiescence, the hallmark of progressive muscle relaxation training.
} 
Table 1

Summary of Controlled Research on the Use of Hypnosis With Conditioned Side Effects

\begin{tabular}{|c|c|c|c|c|c|}
\hline Study & Patients & Study design & Treatment protocol & $\begin{array}{l}\text { Assessment } \\
\text { instruments }\end{array}$ & Results \\
\hline $\begin{array}{l}\text { Redd, Andresen, \& } \\
\text { Minagawa (1982) }\end{array}$ & $\begin{array}{l}N=6 \text { adults; } \mathrm{Dx}= \\
\text { varied: } 4 \text { breast, } 1 \\
\text { lung, } 1 \\
\text { hematologic; } \mathrm{CP}= \\
\text { varied }\end{array}$ & $\begin{array}{l}\text { Single-subject } \\
\text { multiple baseline }\end{array}$ & $\begin{array}{l}7-14 \text { baseline, and } \\
5-7 \text { treatment } \\
\text { sessions }\end{array}$ & $\begin{array}{l}\text { RN observation of } \\
\text { BP; Pt ratings of N }\end{array}$ & $\begin{array}{l}\text { Decreased } \mathrm{N} \text { and } \mathrm{V} \\
\text { during all } \\
\text { treatment sessions } \\
\text { for all patients }\end{array}$ \\
\hline $\begin{array}{l}\text { Zeltzer, Kellerman, } \\
\text { Ellenberg, \& Dash } \\
\text { (1983) }\end{array}$ & $\begin{array}{l}N=12 \text { adolescents; } \\
D x=\text { varied } ; C P= \\
\text { varied }\end{array}$ & $\begin{array}{l}\text { Single-subject, pre- } \\
\text { and post- } \\
\text { intervention }\end{array}$ & $\begin{array}{l}1 \text { baseline, and } 1 \\
\text { treatment session }\end{array}$ & $\begin{array}{l}\text { Pt record of } \\
\text { frequency } \\
\text { duration and } \\
\text { severity of V; Pt } \\
\text { report of anxiety, } \\
\text { health locus of } \\
\text { control, illness } \\
\text { impact, and self- } \\
\text { esteem }\end{array}$ & $\begin{array}{l}8 \text { of } 12 \text { Pts reduced } \\
\text { frequency and } \\
\text { severity of } V ; 6 \text { of } \\
12 \text { Pts reduced } \\
\text { duration of V. } 1 \text { Pt } \\
\text { did not benefit; } 3 \\
\text { Pts rejected } \\
\text { hypnosis }\end{array}$ \\
\hline $\begin{array}{l}\text { LeBaron \& Zeltzer } \\
\quad(1984)\end{array}$ & $\begin{array}{c}N=8 \text { adolescents; } \\
\text { Dx }=6 \\
\text { hematologic, } 2 \\
\text { bone; } \mathrm{CP}=\text { varied }\end{array}$ & $\begin{array}{l}\text { Single-subject, } \\
\text { multiple baseline }\end{array}$ & $\begin{array}{l}2-3 \text { baseline, and 2- } \\
3 \text { treatment } \\
\text { sessions }\end{array}$ & $\begin{array}{l}\text { Pt ratings of } \mathrm{N}, \mathrm{V}, \\
\text { bother, and } \\
\text { disruption; parent } \\
\text { ratings of } \mathrm{N}, \mathrm{V}, \\
\text { bother, and } \\
\text { disruption }\end{array}$ & $\begin{array}{l}\text { Reduced N, V, } \\
\text { bother, and } \\
\text { disruption of } \\
\text { activities }\end{array}$ \\
\hline $\begin{array}{l}\text { Zeltzer, LeBaron, \& } \\
\text { Zeltzer (1984b) }\end{array}$ & $\begin{array}{l}N=19 \text { adolescents; } \\
D x=14 \\
\text { hematologic, } 5 \\
\text { bone; } C P=\text { varied }\end{array}$ & $\begin{array}{l}\text { Group comparison: } \\
\text { hypnosis vs. } \\
\text { supportive } \\
\text { counseling }\end{array}$ & $\begin{array}{l}2 \text { baseline, } 2 \\
\text { treatment, and } 1 \\
\text { follow-up session }\end{array}$ & $\begin{array}{l}\text { Pt ratings of } \mathrm{N}, \mathrm{V}, \\
\text { and bother; parent } \\
\text { ratings of } \mathrm{N}, \mathrm{V}, \\
\text { and bother }\end{array}$ & $\begin{array}{l}\text { Reduced N, V, and } \\
\text { bother for both } \\
\text { groups during } \\
\text { training and } \\
\text { follow-up. No } \\
\text { differences were } \\
\text { found between the } \\
\text { two interventions }\end{array}$ \\
\hline $\begin{array}{l}\text { Cotanch, } \\
\text { Hockenberry, \& } \\
\text { Herman (1985) }\end{array}$ & $\begin{array}{l}N=12 \text { children and } \\
\text { adolescents; } \mathrm{Dx}= \\
8 \text { pediatric } \\
\text { sarcomas, } 2 \\
\text { hematologic, } 2 \\
\text { other }\end{array}$ & $\begin{array}{l}\text { Group comparison: } \\
\text { self-hypnosis vs. } \\
\text { standard treatment } \\
\text { control }\end{array}$ & $\begin{array}{l}\text { No baseline session, } \\
1 \text { training session, } \\
\text { and } 2 \text { follow-up } \\
\text { sessions }\end{array}$ & $\begin{array}{l}\text { Pt ratings of } \mathrm{N}, \mathrm{V} \text {, } \\
\text { and bother; } \mathrm{RN} \\
\text { ratings of } \mathrm{N} \text { and } \\
\text { bother; } \mathrm{RN} \\
\text { observation of } \mathrm{V} \\
\text { and oral intake }\end{array}$ & $\begin{array}{l}\text { In comparison with } \\
\text { controls, hypnosis } \\
\text { Pts experienced } \\
\text { decreased } \\
\text { frequency, } \\
\text { amount, severity, } \\
\text { and duration of V; } \\
\text { decreased intensity } \\
\text { and duration of N; } \\
\text { decreased bother } \\
\text { during } \\
\text { chemotherapy; } \\
\text { and greater oral } \\
\text { intake following } \\
\text { chemotherapy }\end{array}$ \\
\hline
\end{tabular}

Note. $\mathrm{N}=$ nausea; $\mathrm{V}=$ vomiting; $\mathrm{RN}=$ registered nurse; $\mathrm{Pt}=$ patient $; \mathrm{Dx}=$ diagnosis; $\mathrm{CP}=$ chemotherapy protocol; $\mathrm{BP}=$ blood pressure.

The initial report was a single-subject investigation (Burish \& Lyles, 1979), which was followed by a series of four group comparison designs (Burish, Carey, Krozely, \& Greco, 1987; Burish \& Lyles, 1981; Carey \& Burish, 1987; Lyles, Burish, Krozely, \& Oldham, 1982). In all of these studies, patients were trained in PMRT and guided imagery during the $30 \mathrm{~min}$ just prior to the chemotherapy injections and underwent chemotherapy while relaxed. Patients were asked to practice PMRT and guided imagery at home between treatments. Measurement of patient benefit included a number of physiological, self-report, and nurse-observation measures, which were collected during three to five training and follow-up sessions.

Overall, the research has demonstrated that training in PMRT and guided imagery can reduce physiological arousal, patient reports of nausea and dysphoria, and nurse reports of nausea and anxiety. In some studies, PMRT-related reductions in vomiting frequency were also observed, although this has not been a consistent finding, largely because of the low baseline frequency of this symptom (e.g., see Lyles et al., 1982). The gains achieved with PMRT and guided imagery have been observed in comparison with untreated control patients (e.g., Burish \& Lyles, 1981) and with placebo control patients (Lyles et al., 1982). Typically, these effects were most salient during and after the chemotherapy infusions as opposed to before the infusions. Moreover, the benefits obtained during therapist-guided training were usually stronger than those achieved during follow-up (i.e., maintenance) sessions when the patient was asked to relax him or herself. Finally, PMRT and guided imagery were 
Table 2

Summary of Controlled Research on the Use of Progressive Muscle Relaxation Training With Conditioned Side Effects

\begin{tabular}{|c|c|c|c|c|c|}
\hline Study & Patients & Study design & Treatment protocol & $\begin{array}{l}\text { Assessment } \\
\text { instruments }\end{array}$ & Results \\
\hline $\begin{array}{l}\text { Burish \& Lyles } \\
\text { (1979) }\end{array}$ & $\begin{array}{l}N=1 \text { adult female; } \\
\mathrm{Dx}=\text { hemoto- } \\
\text { logic; } \mathrm{CP}=\text { not } \\
\text { reported }\end{array}$ & $\begin{array}{l}\text { Single-subject, } \\
\text { multiple-phase }\end{array}$ & $\begin{array}{l}1 \text { baseline, } 2 \text { training, } \\
2 \text { follow-up, } 2 \\
\text { more training, and } \\
4 \text { more follow-up } \\
\text { sessions }\end{array}$ & $\begin{array}{l}\text { BP; PR; Pt ratings of } \\
\text { anxiety, } \\
\text { depression, and } N \text {; } \\
\text { RN ratings of } \\
\text { anxiety, N, and V }\end{array}$ & $\begin{array}{l}\text { During training, } \\
\text { booster, and } \\
\text { second follow-up, } \\
\text { Pt reduced N, } \\
\text { anxiety, depres- } \\
\text { sion, PR, BP, and } \\
\text { frequency } \\
\text { of } V\end{array}$ \\
\hline $\begin{array}{l}\text { Burish \& Lyles } \\
\quad(1981)\end{array}$ & $\begin{array}{l}N=16 \text { adults; } \mathrm{Dx}= \\
\text { varied; } \mathrm{CP}= \\
\text { varied }\end{array}$ & $\begin{array}{l}\text { Group comparison: } \\
\text { PMRT plus GI vs. } \\
\text { no treatment }\end{array}$ & $\begin{array}{l}1 \text { baseline, } 2 \text { training, } \\
\text { and } 2 \text { follow-up } \\
\text { sessions }\end{array}$ & $\begin{array}{l}\text { BP; PR; Pt ratings of } \\
\text { anxiety, hostility, } \\
\text { depression, and N; } \\
\text { RN ratings of } \\
\text { anxiety, N, and V }\end{array}$ & $\begin{array}{l}\text { PMRT Pts reduced } \\
\text { hostility, anxiety, } \\
\text { depression, } N \text {, and } \\
\text { PR during follow- } \\
\text { up in comparison } \\
\text { with controls; no } \\
\text { differences be- } \\
\text { tween groups } \\
\text { on V }\end{array}$ \\
\hline Cotanch (1983) & $\begin{array}{l}N=12 \text { adults; } \mathrm{Dx}= \\
\quad \text { varied; } \mathrm{CP}= \\
\text { varied }\end{array}$ & $\begin{array}{l}\text { Single subject, pre- } \\
\text { and post- } \\
\text { intervention } \\
\text { design }\end{array}$ & $\begin{array}{l}1 \text { baseline and } 5 \\
\text { training sessions }\end{array}$ & $\begin{array}{l}\text { During } \\
\text { chemotherapy: } \\
\text { BP; } P R ; R R ; P t \\
\text { ratings of anxiety, } \\
\mathrm{N} \text {, and } \mathrm{V} ; \mathrm{RN} / \\
\text { family ratings of } \mathrm{N} \\
\text { and } \mathrm{V}\end{array}$ & $\begin{array}{l}\text { In comparison with } \\
\text { baseline, } 9 \text { of } 12 \\
\text { Pts showed some } \\
\text { decrease in } N \text { and } \\
\mathrm{V} ; \text { caloric intake } \\
\text { increase in all Pts; } \\
\mathrm{PR}, \mathrm{RR} \text {, and trait } \\
\text { anxiety were also } \\
\text { reduced }\end{array}$ \\
\hline $\begin{array}{l}\text { Dahlquist, Gil, } \\
\text { Armstrong, } \\
\text { Ginsberg, \& Jones } \\
\text { (1985) }\end{array}$ & $\begin{array}{l}N=3 \text { children, aged } \\
11-14 ; \mathrm{Dx}=1 \\
\text { Burkitts } \\
\text { lymphoma, } 2 \\
\text { osteosarcoma of } \\
\text { the femur }\end{array}$ & $\begin{array}{l}\text { Multiple baseline } \\
\text { across subjects }\end{array}$ & $\begin{array}{l}\text { Baseline: } 2-15 \\
\text { preintervention } \\
\text { venipunctures; } \\
\text { treatment: } 5-12 \\
\text { sessions of } \\
\text { relaxation } \\
\text { training } \\
\text { combined with } \\
\text { pleasant imagery } \\
\text { and positive self- } \\
\text { talk }\end{array}$ & $\begin{array}{l}\text { Observational Scale } \\
\text { of Behavioral } \\
\text { Distress; parent, } \\
\text { medical staff, and } \\
\text { Pt ratings of } \\
\text { distress }\end{array}$ & $\begin{array}{l}\text { 46-68\% reductions } \\
\text { from baseline } \\
\text { levels of observed } \\
\text { behavioral distress } \\
\text { during veni- } \\
\text { punctures were } \\
\text { found during } \\
\text { intervention; } \\
\text { medical staff and } \\
\text { Pt ratings of } \\
\text { distress during } \\
\text { venipunctures also } \\
\text { decreased during } \\
\text { intervention }\end{array}$ \\
\hline
\end{tabular}


Table 2 (continued)

\begin{tabular}{|c|c|c|c|c|c|}
\hline Study & Patients & Study design & Treatment protocol & $\begin{array}{l}\text { Assessment } \\
\text { instruments }\end{array}$ & Results \\
\hline $\begin{array}{l}\text { Burish, Carey, } \\
\text { Krozely, \& Greco } \\
(1987)\end{array}$ & $\begin{array}{l}N=24 \text { adults; } \mathrm{Dx}= \\
9 \text { breast, } 4 \text { lung, } 10 \\
\text { gynecologic, } 1 \\
\text { hematologic; } \mathrm{CP}= \\
\text { varied }\end{array}$ & $\begin{array}{l}\text { Group comparison: } \\
\text { PMRT plus GI vs. } \\
\text { no-treatment } \\
\text { control }\end{array}$ & $\begin{array}{l}3 \text { training and } 2 \\
\text { follow-up sessions. } \\
\text { N.B.: Intervention } \\
\text { initially delivered } \\
\text { before Pt's first } \\
\text { chemotherapy } \\
\text { treatment }\end{array}$ & $\begin{array}{l}\text { During } \\
\text { chemotherapy: } \\
\text { BP; PR; Pt ratings } \\
\text { of anxiety, } \\
\text { hostility, } \\
\text { depression, and } \mathrm{N} \text {; } \\
\text { RN ratings of } \\
\text { anxiety, } \mathrm{N} \text {, and } \mathrm{V} \\
\text { Following } \\
\text { chemotherapy: } \mathrm{Pt} \\
\text { ratings of anxiety, } \\
\mathrm{N} \text {, and } \mathrm{V} \text { for } 3 \\
\text { days }\end{array}$ & $\begin{array}{l}\text { PMRT Pts, in } \\
\text { comparison with } \\
\text { controls, reported } \\
\text { less severe and } \\
\text { prolonged N; less } \\
\text { anxiety, } \\
\text { depression, and } \\
\text { hostility and lower } \\
\text { PRs and BPs. } \\
\text { These differences } \\
\text { were most salient } \\
\text { during Sessions } 4 \\
\text { and } 5\end{array}$ \\
\hline $\begin{array}{l}\text { Carey \& Burish } \\
\quad(1987)\end{array}$ & $\begin{array}{l}N=45 \text { adults; } \mathrm{Dx}= \\
\quad \text { varied; } \mathrm{CP}= \\
\text { varied }\end{array}$ & $\begin{array}{l}\text { Group comparison: } \\
\text { PMRT plus GI; } \\
\text { delivered by (a) } \\
\text { professionals, (b) } \\
\text { volunteers, or (c) } \\
\text { audiotape vs. no- } \\
\text { treatment control }\end{array}$ & $\begin{array}{l}1 \text { baseline, } 3 \text { training, } \\
\text { and } 1 \text { follow-up } \\
\text { session }\end{array}$ & $\begin{array}{l}\text { During } \\
\text { chemotherapy: } \\
\text { BP; PR; RR; Pt } \\
\text { ratings of } \\
\text { dysphoria and N; } \\
\text { RN ratings of } \\
\text { anxiety, N, and V } \\
\text { Following } \\
\text { chemotherapy: Pt } \\
\text { ratings of anxiety, } \\
\mathrm{N}, \mathrm{V} \text {, and food } \\
\text { intake }\end{array}$ & $\begin{array}{l}\text { Overall, Pts trained } \\
\text { in PMRT by } \\
\text { professional } \\
\text { therapists } \\
\text { experienced less } \\
\text { distress than did } \\
\text { Pts trained by } \\
\text { volunteers, Pts } \\
\text { who used } \\
\text { videotaped } \\
\text { PMRT, and } \\
\text { control Pts. }\end{array}$ \\
\hline
\end{tabular}

Note. $\mathrm{N}=$ nausea; $\mathrm{V}=$ vomiting; $\mathrm{RN}=$ registered nurse, $\mathrm{Pt}=$ patient; $\mathrm{Dx}=$ diagnosis; $\mathrm{CP}=$ chemotherapy protocol; $\mathrm{PMRT}=$ progressive muscle relaxation training; $\mathrm{GI}=$ guided imagery; $\mathrm{BP}=$ blood pressure; $\mathrm{PR}=$ pulse rate; $\mathrm{RR}=$ respiration rate; $\mathrm{SBP}=$ systolic blood pressure; $\mathrm{DBP}=$ diastolic blood pressure.

shown to be effective not only in ameliorating distress in veteran chemotherapy patients (e.g., Lyles et al., 1982) but also in preventing or at least delaying the apparent development of psychological side effects in new patients (Burish et al., 1987).

Cotanch and her associates have also conducted research that supports the efficacy of PMRT and guided imagery. The first study (Cotanch, 1983) used an own-control design in which 12 adult patients underwent one baseline chemotherapy session followed by five chemotherapy sessions during which they were trained in PMRT with guided imagery. Results indicated that PMRT and guided imagery produced reductions in physiological arousal, nausea, vomiting, and anxiety in 9 of 12 patients. In a follow-up study (Cotanch \& Strum, 1985), PMRT and guided imagery delivered by audiotaped instructions were compared to a placebo treatment (therapist present while patient listened to music). The relaxation procedure was found to be more effective than the placebo tape in lowering physiological arousal and trait anxiety and in increasing postchemotherapy caloric intake. Unfortunately, no standard treatment control group was included in this study, making evaluation of the audiotaped instructions difficult.

Finally, Dahlquist, Gil, Armstrong, Ginsberg, and Jones (1985) reported on the use of cue-controlled muscle relaxation, controlled breathing, pleasant imagery, and positive self-statements with 3 children in a multiple baseline design. After this treatment, behavioral distress as observed by trained assistants was reduced $46-68 \%$ from baseline levels. Medical staff ratings of the patient's distress and patient self-reports of distress were also reduced as a result of treatment.

In summary, PMRT and guided imagery have been shown in several well-controlled investigations to be effective for the reduction of nausea, physiological arousal, and negative affect and for increasing food intake during the days after chemotherapy. Reductions in vomiting have not been consistently reported, although this may reflect less severe baseline symptoms in the patients studied. Finally, the effects of PMRT and guided imagery appear to be strongest during training, although modest benefits have also been observed during follow-up.

\section{Systematic Desensitization}

Systematic desensitization (SD) is a procedure that has been used widely in the treatment of phobias, sexual dysfunctions, and other anxiety-related disorders (Wolpe, 1958). The procedure basically consists of teaching a patient a relaxation skill, commonly some form of relaxation training, and then exposing the patient to progressively more anxiety-provoking stimuli. The goal is to have these stimuli elicit or be accompanied by a relaxation response rather than the anxiety response heretofore elicited by them. The underlying process responsible for the effectiveness of SD has been a topic of considerable recent debate; hypothesized mechanisms of action include counterconditioning, extinction, habituation, attentional control, and several others (see Masters, Burish, Hollon, \& Rimm, 1987, for a review). 
Table 3

Summary of Controlled Research on the Use of Systematic Desensitization With Conditioned Side Effects

\begin{tabular}{|c|c|c|c|c|c|}
\hline Study & Patients & Study design & Treatment protocol & $\begin{array}{l}\text { Assessment } \\
\text { instruments }\end{array}$ & Results \\
\hline $\begin{array}{l}\text { Morrow \& Morrell } \\
\quad(1982)\end{array}$ & $\begin{array}{l}N=60 \text { adults; } \mathrm{Dx}= \\
\text { varied; } \mathrm{CP}= \\
\text { varied }\end{array}$ & $\begin{array}{l}\text { Group comparison: } \\
\text { SD vs. counseling } \\
\text { vs. no-treatment } \\
\text { counseling }\end{array}$ & $\begin{array}{l}2 \text { baseline and } 2 \\
\text { follow-up sessions. } \\
\text { SD and counseling } \\
\text { occurred between } \\
\text { Pts' fourth and } \\
\text { fifth chemotherapy } \\
\text { sessions }\end{array}$ & $\begin{array}{l}\text { Pt report of } \mathrm{N}, \mathrm{V}, \\
\text { anxiety, and } \\
\text { helplessness }\end{array}$ & $\begin{array}{l}\text { SD Pts reported less } \\
\text { frequent and } \\
\text { severe AN and AV } \\
\text { than did Pts in } \\
\text { other groups. No } \\
\text { differences were } \\
\text { observed in } \\
\text { anxiety or } \\
\text { helplessness across } \\
\text { conditions }\end{array}$ \\
\hline Morrow (1986) & $\begin{array}{l}N=92 \text { adults; } \mathrm{Dx}= \\
\text { varied; } \mathrm{CP}= \\
\text { varied }\end{array}$ & $\begin{array}{l}\text { Group comparison: } \\
\text { SD vs. PMRT vs. } \\
\text { counseling vs. no- } \\
\text { treatment control }\end{array}$ & $\begin{array}{l}2 \text { baseline and } 2 \\
\text { follow-up sessions. } \\
\text { SD, PMRT, and } \\
\text { counseling } \\
\text { occurred between } \\
\text { Pts' fourth and } \\
\text { fifth chemotherapy } \\
\text { sessions }\end{array}$ & $\begin{array}{l}\text { Pt report of } \mathrm{N} \text { state } \\
\text { anxiety, trait } \\
\text { anxiety }\end{array}$ & $\begin{array}{l}\text { SD Pts reported less } \\
\text { AN, state anxiety, } \\
\text { and trait anxiety } \\
\text { than did Pts in } \\
\text { other groups; SD } \\
\text { and PMRT Pts } \\
\text { reported less } \\
\text { posttreatment N } \\
\text { than did Pts in } \\
\text { other groups }\end{array}$ \\
\hline
\end{tabular}

Note. $\mathrm{N}=$ nausea; $\mathrm{V}=$ vomiting; $\mathrm{AN}=$ anticipatory nausea; $\mathrm{AV}=$ anticipatory vomiting; $\mathrm{RN}=$ registered nurse; $\mathrm{Pt}=$ patient; $\mathrm{Dx}=$ diagnosis; $\mathrm{CP}=$ chemotherapy protocol; $\mathrm{PMRT}=$ progressive muscle relaxation training; $\mathrm{SD}=$ systematic desensitization.

Support for the use of SD with cancer chemotherapy patients comes from both uncontrolled case studies (e.g., Hailey \& White, 1983; Hoffman, 1982-1983; West \& Piccionne, 1982) and from controlled research (summarized in Table 3). Morrow and Morrell (1982) studied 60 patients within a group comparison format to determine the relative efficacy of a self-control version of systematic desensitization, supportive counseling, and no treatment. Patients in the SD condition were taught PMRT and instructed to imagine themselves staying calm and relaxed in a number of situations, beginning with the day before chemotherapy and progressing through the actual chemotherapy infusion. Patients were seen twice in the therapist's office and were then followed for two subsequent chemotherapy sessions. During follow-up, the patients receiving SD reported reduced frequency and severity, and a shortened duration, of both anticipatory nausea and vomiting, in comparison with counseling and control patients.

In a subsequent report, Morrow (1986) compared patients who received SD, counseling, or no treatment (most of the patients in these groups were the same as those participating in the Morrow \& Morrell, 1982, study) with a new group of patients that received PMRT only. The procedures used for the first three groups were identical to those used in the Morrow and Morrell study; the PMRT group followed procedures identical to those of the SD group except that no cognitive hierarchy was used. The results suggested that SD reduced anticipatory nausea, state anxiety, and trait anxiety ${ }^{4}$ more than the other three treatments did; these other treatments did not differ from each other on these variables. SD and PMRT produced changes in posttreatment nausea and vomiting that were comparable and significantly greater than those produced by the counseling or no treatment groups, which did not differ from each other.
Because Morrow (1986) used different procedures to administer PMRT from those of other researchers (e.g., guided imagery was not given, and relaxation was not provided during chemotherapy treatments, nor were patients specifically told to use the relaxation during their treatments), he appropriately cautioned against viewing this study as a direct comparison of SD and PMRT. However, the data do suggest that SD is less effective without the cognitive hierarchy.

In summary, Morrow's research on SD suggests that this procedure can provide an effective procedure for reducing conditioned responses to cancer chemotherapy.

\section{Biofeedback Combined With PMRT and Guided Imagery}

Biofeedback, a commonly used treatment method in behavioral medicine, involves training an individual to control physiological responses, such as systolic blood pressure or heart rate, by using external monitoring devices. Such devices indicate when a desired change occurs, and the patient seeks to learn and then to bring under conscious control the behaviors associated with the desired change. The combined use of biofeedback, PMRT, and guided imagery with cancer chemotherapy patients has been evaluated in two studies (summarized in Table 4).

Burish, Shartner, and Lyles (1981) implemented a multiple baseline design to study the combined effectiveness of an electromyograph (EMG) biofeedback and PMRT intervention with

\footnotetext{
${ }^{4}$ It is not clear why trait anxiety would change as a result of a shortterm behavioral intervention, though it has been reported in several studies.
} 
Table 4

Summary of Controlled Research on the Use of Biofeedback With Conditioned Side Effects

\begin{tabular}{|c|c|c|c|c|c|}
\hline Study & Patients & Study design & Treatment protocol & $\begin{array}{l}\text { Assessment } \\
\text { instruments }\end{array}$ & Results \\
\hline $\begin{array}{l}\text { Burish, Shartner, \& } \\
\text { Lyles (1981) }\end{array}$ & $\begin{array}{l}N=1 \text { adult } ; \mathrm{Dx}= \\
\text { adenocarcinoma; } \\
\mathrm{CP}=\text { not reported }\end{array}$ & $\begin{array}{l}\text { Single-subject } \\
\text { multiple baseline }\end{array}$ & $\begin{array}{l}3 \text { baseline, } 4 \text { training, } \\
\text { and } 3 \text { follow-up } \\
\text { sessions. } \\
\text { Intervention } \\
\text { involved PMRT } \\
\text { and multiple-site } \\
\text { EMG biofeedback } \\
\text { training }\end{array}$ & $\begin{array}{l}\text { BP; PR; EMG } \\
\text { activity; Pt ratings } \\
\text { of anxiety, N, and } \\
\text { V }\end{array}$ & $\begin{array}{l}\text { In comparison with } \\
\text { baseline, the Pt } \\
\text { reduced PR, BP, } \\
\text { EMG levels, and } \\
\text { reported less } \\
\text { anxiety and N. } \\
\text { These } \\
\text { improvements } \\
\text { were obtained } \\
\text { during both } \\
\text { training and } \\
\text { follow-up }\end{array}$ \\
\hline $\begin{array}{l}\text { Shartner, Burish, \& } \\
\text { Carey (1985) }\end{array}$ & $\begin{array}{l}N=12 ; \mathrm{Dx}=\text { varied; } \\
\mathrm{CP}=\text { varied }\end{array}$ & $\begin{array}{l}\text { Group comparison: } \\
\text { thermal } \\
\text { biofeedback with } \\
\text { PMRT vs. EMG } \\
\text { biofeedback with } \\
\text { PMRT vs. control }\end{array}$ & $\begin{array}{l}4 \text { training and } 1 \\
\text { follow-up session }\end{array}$ & $\begin{array}{l}\text { During } \\
\text { chemotherapy: } \\
\text { BP; PR; Pt ratings } \\
\text { of anxiety, } \\
\text { hostility, } \\
\text { depression, and N; } \\
\text { RN ratings of } \\
\text { anxiety, N, and V } \\
\text { Following } \\
\text { chemotherapy: Pt } \\
\text { ratings of anxiety, } \\
\mathrm{N} \text {, and V for } 3 \\
\text { days }\end{array}$ & $\begin{array}{l}\text { In comparison with } \\
\text { the control group, } \\
\text { treated Pts } \\
\text { reported less } \\
\text { anxiety, hostility, } \\
\text { depression, and N } \\
\text { during and after } \\
\text { chemotherapy. No } \\
\text { differences in V } \\
\text { among groups. }\end{array}$ \\
\hline
\end{tabular}

Note. $\mathrm{N}=$ nausea $\mathrm{V}=$ vomiting; $\mathrm{RN}=$ registered nurse $\mathrm{Pt}=$ patient $; \mathrm{Dx}=$ diagnosis $; \mathrm{CP}=$ chemotherapy protocol $; \mathrm{PMRT}=$ progressive muscle relaxation training; $\mathrm{BP}=$ blood pressure; $\mathrm{PR}=$ pulse rate $\mathrm{EMG}=$ electromyograph.

an adult patient who had developed psychological symptoms in response to her chemotherapy. During the four chemotherapy sessions in which the patient received the intervention and during three subsequent follow-up sessions, she showed reductions from baseline in physiological arousal and reported less anxiety and nausea. In a follow-up study, Shartner, Burish, and Carey (1985) randomly assigned 12 adults to (a) EMG biofeedback and PMRT, (b) thermal biofeedback and PMRT, or (c) a control condition. Patients were studied over five sessions. The results indicated that both forms of biofeedback, when combined with PMRT, reduced the negative affect and nausea associated with chemotherapy. Taken together, these two reports suggest that the combined use of biofeedback with PMRT and guided imagery appears to be a promising intervention. Future research might study larger samples of patients and employ a dismantling strategy (Lang, 1969) so that biofeedback can be assessed independently of PMRT and guided imagery.

\section{Distraction Techniques}

A recent innovation in the treatment of psychological side effects has involved the use of attentional diversion/cognitive distraction techniques. This treatment approach was considered because of related research in the treatment of acute pain (see McCaul \& Malott, 1984), as well as interest in the mechanism or mechanisms by which the other behavioral interventions exerted their impact (this point is addressed more fully in the Discussion section). Distraction techniques attempt to focus patients' attention on pleasant stimuli or activities, thereby directing attention away from unpleasant sensations and from potential CSs. Distraction might be achieved by any of a large number of tasks (e.g., pleasant imagery, music, focal point attention), but in the chemotherapy context, it has been most commonly accomplished by the use of external devices, particularly video games. The research using distraction to reduce the side effects of chemotherapy is described in Table 5.

In the first published study of distraction, Kolko and Rickard-Figueroa (1985) used a multiple baseline design to study the efficacy of video games in 3 adolescent cancer patients. When the patients used the video games, they experienced a reduction in the number of general anticipatory symptoms (e.g., nausea, insomnia, cold hands) displayed during the $24 \mathrm{hr}$ prior to chemotherapy and a decrease in the aversiveness of the postchemotherapy side effects. When the games (distraction) were not available, the number of anticipatory symptoms returned to baseline levels.

Redd et al. (1987) conducted two studies to evaluate a video game-based distractor in 26 pediatric patients undergoing chemotherapy. In the first study, which used a group comparison design, these authors found a significant decrease in the intensity of nausea for those patients who employed distraction in comparison with control patients who did not. In a subsequent study, using a repeated measures reversal design (i.e., no distraction baseline, introduction to distraction, return to no dis- 
Table 5

Summary of Controlled Research on the Use of Distraction With Conditioned Side Effects

\begin{tabular}{|c|c|c|c|c|c|}
\hline Study & Patients & Study design & Treatment protocol & $\begin{array}{l}\text { Assessment } \\
\text { instruments }\end{array}$ & Results \\
\hline $\begin{array}{l}\text { Kolko \& Rickard- } \\
\text { Figueroa (1985) }\end{array}$ & $\begin{array}{l}N=3 \text { adolescent } \\
\text { males; } \mathrm{Dx}=\text { acute } \\
\text { lymphocitic } \\
\text { leukemia; } \mathrm{CP}= \\
\text { not reported }\end{array}$ & $\begin{array}{l}\text { Single subject, } \\
\text { multiple baseline } \\
\text { (ABAB) }\end{array}$ & $\begin{array}{l}\text { 3-5 baseline, } 3 \\
\text { intervention, } 3 \\
\text { withdrawal and } \\
\text { intervention } \\
\text { sessions. } \\
\text { Intervention } \\
\text { involved a } \\
\text { cognitive } \\
\text { distractor, i.e., } \\
\text { access to video } \\
\text { games }\end{array}$ & $\begin{array}{l}\text { Pt report of general } \\
\text { distress, anxiety, } \\
\text { and } \\
\text { chemotherapy- } \\
\text { related symptoms; } \\
\text { observer rating of } \\
\text { distress }\end{array}$ & $\begin{array}{l}\text { In comparison with } \\
\text { baseline, } \\
\text { distraction led to } \\
\text { reduced number } \\
\text { of anticipatory } \\
\text { symptoms and to } \\
\text { reduced severity of } \\
\text { postchemotherapy } \\
\text { side effects }\end{array}$ \\
\hline $\begin{array}{l}\text { Redd, Jacobsen, Die- } \\
\text { Trill, Dermatis, } \\
\text { McEvoy, \& } \\
\text { Holland (1987) }\end{array}$ & $\begin{array}{l}\text { Study } 1 \\
\qquad \begin{array}{l}N=26 \text { children } \\
\text { and adolescents; } \\
\mathrm{Dx}=\text { varied; } \mathrm{CP}= \\
\text { varied }\end{array}\end{array}$ & $\begin{array}{l}\text { Group comparison: } \\
\text { video distraction } \\
\text { vs. placebo control }\end{array}$ & $\begin{array}{l}1 \text { baseline and } 1 \\
\text { intervention } \\
\text { session }\end{array}$ & $P t$ rating of $N$ & $\begin{array}{l}\text { In comparison with } \\
\text { control Pts, Pts } \\
\text { using distraction } \\
\text { experienced } \\
\text { decreased N }\end{array}$ \\
\hline $\begin{array}{l}\text { Greene, Seime, \& } \\
\text { Smith (1985) }\end{array}$ & $\begin{array}{l}N=1 \text { adult; } \mathrm{Dx}= \\
\text { adenocarcinoma } \\
\text { of the stomach; } \\
\mathrm{CP}= \\
\text { Fluorouracil, } \\
\text { Adriomycin, and } \\
\text { Mitomycin }\end{array}$ & $\begin{array}{l}\text { Single subject, } \\
\text { multiple baseline } \\
\text { (ABABC) }\end{array}$ & $\begin{array}{l}3 \text { baseline, } 3 \text { video } \\
\text { distraction, } 2 \\
\text { withdrawal, } 3 \\
\text { video distraction, } \\
6 \text { relaxation } \\
\text { training }\end{array}$ & $\begin{array}{l}\text { Pt report of N and V; } \\
\text { PR; SBP; DBP. }\end{array}$ & $\begin{array}{l}\text { Initially, video } \\
\text { distraction } \\
\text { reduced ANV; } \\
\text { treatment effects } \\
\text { not maintained } \\
\text { with distraction. } \\
\text { Relaxation } \\
\text { reduced ANV and } \\
\text { effect maintained. }\end{array}$ \\
\hline
\end{tabular}

Note. $\mathrm{N}=$ nausea; $\mathrm{V}=$ vomiting; $\mathrm{ANV}=$ anticipatory nausea and vomiting; $\mathrm{Pt}=$ patient; $\mathrm{Dx}=$ diagnosis; $\mathrm{CP}=$ chemotherapy protocol; $\mathrm{BP}=$ blood pressure; $\mathrm{PR}=$ pulse rate; $\mathrm{RR}=$ respiration rate; $\mathrm{SBP}=$ systolic blood pressure; $\mathrm{DBP}=$ diastolic blood pressure.

traction, return to distraction), Redd et al. found additional evidence for the efficacy of distraction, both for nausea and for anxiety. Interestingly, Redd et al. reported that the introduction and withdrawal of the opportunity to play video games did not consistently influence physiological indices of arousal.

In the only study of distraction reported thus far with adults, Greene, Seime, and Smith (1985) compared the efficacy of video games with relaxation training for the reduction of anticipatory nausea and vomiting. These authors implemented a complex, multiple-baseline design that included five phases: (a) no intervention, (b) video distraction, (c) removal of the distraction device (i.e., no intervention), (d) video distraction, and (e) relaxation training. This single-subject study took place over 18 chemotherapy sessions during a 9-month period. The results were consistent with earlier reports in that video distraction initially inhibited anticipatory nausea and vomiting and that these gains were not maintained when the distractor was unavailable. In contrast with previous work, however, the authors reported that the efficacy of distraction was attenuated with continued use (i.e., during Phase 4); moreover, the subsequent use of relaxation was associated with a reduction in anticipatory symptoms. Although a single-subject study of this sort does not war- rant firm conclusions, these results do suggest that (a) the effectiveness of distraction may lessen with extended use and (b) the benefits of relaxation may be more permanent. It may be that the poor maintenance of this distractor was related to its lessening novelty, whereas the comparatively better transfer of treatment gains with PMRT (and related techniques) may result from the fact that they provide patients with a self-control technique that is more permanent (see Thoresen \& Mahoney, 1974).

Overall, preliminary research suggests that interventions that use external distractors (e.g., video games) do appear to reduce chemotherapy-related responses, at least initially, as long as the distracting stimuli are available. However, these results need to be accepted with caution until they have been replicated in controlled studies using larger patient samples. Moreover, at least four important questions are unresolved and warrant further investigation. First, does repeated use of an external distractor (e.g., video games) reduce that distractor's novelty and, therefore, efficacy over time? Second, can treatment gains achieved with external distraction be maintained after the distractor is withdrawn and the patient is left to his or her own resources? Third, is an internally generated distractor, which can change over time and retain its novelty, be more effective than an exter- 
nally provided distractor, which may be more stable? And finally, how does the use of an internally generated distractor differ, if at all, from hypnosis or guided imagery?

\section{Summary}

Within the past 10 years, a number of case reports and controlled studies have assessed the efficacy of psychological interventions for reducing the side effects resulting from cancer chemotherapy. Controlled investigations have been completed for five interventions: hypnosis, progressive muscle relaxation training with guided imagery, systematic desensitization, EMG and thermal biofeedback, and cognitive distraction. This research suggests that hypnosis, PMRT and guided imagery, and SD can successfully reduce the psychological side effects that accompany cancer chemotherapy, including nausea, vomiting, and negative affect, and perhaps can also increase caloric intake in the days after chemotherapy. The studies on biofeedback and cognitive distraction are also positive in outcome, but because of the small number of subjects observed, these studies are only suggestive in nature. Overall, the data suggest that psychological interventions can effectively reduce much of the distress associated with cancer chemotherapy.

\section{Discussion}

Most of the investigations on the psychological treatment of chemotherapy-related side effects have focused on the relatively simple question, Are psychological interventions efficacious? As the foregoing review suggests, an affirmative answer to this question appears warranted. Increasingly, therefore, research will be devoted to subtler questions such as, With whom do such interventions work? How do the interventions exert their impact? How can we maximize the clinical utility and availability of these interventions? We now focus our attention on these questions.

\section{Factors Associated With Treatment Acceptance and Outcome}

Although psychological interventions for reducing chemotherapy-related side effects are effective with many patients, they are not effective with all patients. At least two types of factors might contribute to this fact. First, not all cancer chemotherapy patients are willing to try or to continue trying psychological interventions. For example, Zeltzer et al. (1983) reported that $25 \%$ ( 3 of 12 ) of the adolescents they studied rejected hypnosis for cultural reasons. Hendler and Redd (1986) found that many chemotherapy patients believed that the hypnotic state is an unconscious, powerful state involving loss of control and that given a choice, they prefer an intervention not labeled "hypnosis." Although the other psychological interventions are less likely than hypnosis to be rejected because of misconceptions about the technique or its goals, in our research we have found that a minority of patients do not pursue these other techniques because they are perceived to involve too much effort or time. This is especially likely for patients who are very ill or weak. In some cases we believe it is possible and clinically beneficial to gently encourage such patients, using the same clinical sensitivity and skill necessary in other treatment contexts, to use the intervention.

Second, not all patients who do try psychological interventions will profit from them. For example, Lyles et al. (1982) reported that even though the majority of their patients profited from PMRT and guided imagery, some showed no change, and a few evinced increased distress on some measures. Research designed to determine whether individual patient characteristics might predict treatment outcome has helped to explain such results. In a reanalysis of data collected in an earlier series of studies, Carey and Burish (1985) found that patients who had high and moderate baseline levels of anxiety were less likely than were low-anxious patients to benefit from PMRT and biofeedback. For such persons, the task of practicing a behavioral intervention such as PMRT may be appraised as an additional stressor that increases, rather than decreases, their discomfort during chemotherapy. In a related study, Burish et al. (1984) reported that cancer chemotherapy patients with an external health locus of control, in comparison with patients without such an orientation, were also more likely to profit from relaxation training. In contrast, no relationship has been found between hypnotic susceptibility and the degree of symptom reduction achieved with hypnosis (Zeltzer et al., 1984b) nor between pretreatment expectancies and outcome on systematic desensitization (Morrow \& Morrell, 1982) or on PMRT (Carey $\&$ Burish, 1987). Although these results should be accepted cautiously because of the small number of patients studied, it appears that cancer chemotherapy patients who have low levels of pretreatment anxiety or who exhibit an external locus of control benefit more than do their high-anxious and nonexternally oriented counterparts. Unfortunately, no research has assessed the contribution of individual difference factors using a multivariate model in which the combined and interactive effects of several variables can be determined. It is possible that such an approach will allow us to account for a greater share of the variance in treatment outcome.

\section{Mechanisms of Action}

Given that psychological techniques can indeed be effective in reducing the conditioned and stress-induced symptoms associated with cancer chemotherapy, it is worthwhile to determine the means by which these techniques exert their impact. The identification of unique and common causal factors across interventions would be theoretically interesting and would also allow for more precise and cost-effective treatment planning. Unfortunately, few studies have provided the comparative and componential analyses required to address directly these issues in a convincing empirical fashion. Despite this lacuna in the research literature, it is possible to describe five hypotheses that may explain, at least in part, the mechanism or mechanisms by which psychological interventions reduce chemotherapy-related distress. We preface our descriptions by acknowledging that these represent hypotheses to be evaluated rather than conclusions to be drawn.

Nonspecific factors. The first hypothesis, which must be considered in any discussion of possible mechanisms, is that the 
effectiveness of the treatment results from the various nonspecific factors associated with the treatment's delivery (Kazdin \& Wilcoxon, 1976). Such nonspecific factors are likely to include positive expectancies of the patient (i.e., the placebo effect; Frank, 1973) as well as the empathy and social support provided by a therapist. Another nonspecific factor, especially relevant with regard to the use of video games with children, is the unconventional nature of the intervention; such an unusual intervention (from a traditional medical perspective) may communicate to patients that despite the rather serious, sterile medical environment, the professionals working with them are indeed interested in their psychological welfare as well as in treating their disease. This message may allay medically related anxieties and prevent common hospital fears from being exacerbated.

In order to test this hypothesis, several studies have included plausible attention-placebo procedures to control for nonspecific factors (e.g., Cotanch \& Strum, 1985; Lyles et al., 1982; Morrow \& Morrell, 1982). In each of these investigations the specific intervention was clearly superior to the placebo condition, which in turn did not differ from the nontreatment control. Moreover, investigators who have studied antiemetic medications (see Siegel \& Longo, 1981) or alternative behavior interventions (e.g., Carey \& Burish, 1987) have demonstrated that positive expectancies and increased attention alone cannot account for treatment efficacy. Thus, although nonspecific factors probably do contribute to the overall impact of the treatments, it is unlikely that these factors account for much of the observed effect.

Physiological relaxation. An alternative explanation for the beneficial effects observed in the chemotherapy context is that such improvements may be attributable to deep somatic restfulness, sometimes called the relaxation response (Benson, 1975). This effect would appear to be produced by four of the five interventions just reviewed (viz., hypnosis, PMRT, SD, and EMG biofeedback). ${ }^{5}$ In this regard, previous clinical research suggests that despite some differences in their effects, these stress-management procedures are quite similar in that they produce "a large global relaxation response" (Lehrer \& Woolfolk, 1984, p. 463; emphasis added).

Within the chemotherapy context, relaxation may exert its effect through one or more of several related pathways, with the degree of relaxation achieved related to level of effectiveness. First, relaxation may reduce symptoms indirectly by reducing generalized physiological arousal; that is, it can be hypothesized that the side effects of chemotherapy often lead to arousal, which in turn may (a) become a conditioned stimulus for those same side effects, (b) be associated with neurotransmitter changes that contribute to conditioned responses, or (c) exacerbate pharmacological, conditioned, or other stress-related symptoms by adding to the overall stressfulness of the situation. Thus, by minimizing general physiological arousal, the interventions may be effective in reducing chemotherapy-related side effects. Second, relaxation may directly inhibit the muscular contractions in the gastrointestinal tract that accompany nausea and vomiting or may indirectly influence such activity by affecting neurochemical changes in the brain that in turn control gastrointestinal activity. Finally, relaxation may pro- duce its effects by increasing the threshold (i.e., decreasing the sensitivity) of the chemoreceptor trigger zone, which is believed to coordinate the vomiting response (Borison \& McCarthy, 1983).

Although these hypotheses are speculative, indirect support for their validity is provided by the following general findings. First, many antiemetic medications (e.g., prochlorperazine) are effective in reducing emesis in part because they produce a physiological sedation effect (Borison \& McCarthy, 1983) that may be similar to, although stronger than, that produced by behavioral relaxation techniques (cf. Lader, 1984). Second, there is ample evidence from other clinical contexts that relaxation produces a general decrease in sympathetic arousal and EMG activity (Borkovec \& Sides, 1979). Finally, Hoffman et al. (1982) have reported that relaxation can result in augmented plasma norepinephrine levels, particularly under conditions of stress. These authors speculated that individuals skilled at deep relaxation are physiologically less responsive to stress, with reduced adrenergic end-organ responsivity. Overall, therefore, the data suggest that deep physiological relaxation may be an active ingredient contributing to the reduction of conditioned and stress-related responses to chemotherapy.

Despite this support for the relaxation mechanism, some research suggests that physiological relaxation cannot explain completely the effectiveness of all the interventions that have been used. Specifically, Kolko and Rickard-Figueroa (1985) and Redd et al. (1987) reported that even patients who exhibited none of the signs of deep relaxation were able to reduce chemotherapy-related symptoms by becoming actively involved in video games. In addition, research by Morrow (1986) suggests that relaxation training alone is not as effective as training that included imagery components.

Counterconditioning. A third explanation for the efficacy of the various treatments, given that many of the symptoms experienced in the chemotherapy setting probably develop through an associative learning process, is counterconditioning. According to this explanation, the pairing of conditioned stimuli (e.g., the sight of the nurse) that formerly elicited nausea and vomiting with feelings of relaxation and comfort counterconditions these stimuli so that in the future they will elicit relaxation, or at least a less stressful state, rather than nausea and vomiting. Direct support for this hypothesis comes from research on SD (Morrow \& Morrell, 1982); indirect support can be gleaned from research on the other interventions (viz., hypnosis, PMRT, and biofeedback), but only if one makes the assumption that patients were aware of the conditioned stimuli present in the chemotherapy environment while they were undergoing the various psychological treatments. If this assumption is valid, it is possible to construe these alternative interventions as a form of in vivo desensitization, whereas Morrow and Morrell's (1982) use of SD can be viewed as the traditional Wolpean version of desensitization.

Although it is an attractive explanation, several problems can be raised with the counterconditioning hypothesis. First, the as-

\footnotetext{
${ }^{s}$ This phenomenon has also been labeled cognitive distraction, attentional control, or absorption.
} 
sumption that patients are attending to the conditioned stimuli present in the chemotherapy context while undergoing hypnosis or PMRT seems dubious; if they are not attending to such conditioned stimuli, then it is less likely that they are being counterconditioned. Second, from a theoretical perspective, it would seem difficult to establish a new association between the $\mathrm{CS}$ and the new response (e.g., relaxation) when a host of negative pharmacological side effects (i.e., the UCR) continue to occur after each chemotherapy treatment. Finally, even if these problems were not present, the effects of SD, even in the wellcontrolled laboratory setting, cannot be attributed completely to counterconditioning, because there are numerous other mechanisms, including those presented here, that appear to be operative (cf. Masters et al., 1987; McGlynn, Mealiea, \& Landau, 1981).

Attentional diversion or redirection. All five of the behavioral interventions reviewed earlier require that patients participate cognitively in the intervention, usually by attending to relaxing or at least nonanxiety-producing situations. It may be that such attentional diversion or redirection may be mediating the therapeutic effect of the various interventions; that is, with patients attending to interesting external (e.g., video games) or internal (e.g., pleasant imagery) stimuli, there is less attention available to focus on unpleasant internal sensations (e.g., nausea) or potential CSs (e.g., drug taste). Such attentional diversion might also be understood from a "stress and coping" perspective (e.g., Lazarus \& Folkman, 1984); that is, if the distracting task is enjoyable (as with pleasant imagery or the use of video games), then appraisal of the overall aversiveness (i.e., threat) of chemotherapy may be lessened, resulting in less dysphoria. This is true even if the distractor produces increased physiological arousal, which results from video games (Redd et al., 1987). Such arousal is believed to result from positive emotions, such as excitement, or from physical effort that is part of the game rather than from a distressing situation (although, conceivably, an improperly chosen distractor could become distressing, such as a video game that was too difficult or produced feelings of failure). Thus, even though some distractors may increase physiological arousal, they can focus attention on a pleasant task and thereby decrease distress.

Direct empirical support for the distraction hypothesis comes from the three reports described earlier (i.e., Greene et al., 1985; Kolko \& Rickard-Figueroa, 1985; Redd et al., 1987). Indirect support for the distraction hypothesis comes from research with other procedures (i.e., hypnosis, PMRT with guided imagery, biofeedback, and systematic desensitization), which all require that the patient attend to specific instructions or actively participate in certain procedures while undergoing chemotherapy. ${ }^{6}$ These instructions and procedures are typically quite absorbing of cognitive capacity, especially to the extent that patients are motivated and interested. Morrow's (1986) study can be seen as supporting this position in that he found that PMRT was not effective when guided imagery was not used during the infusion time; that is, Morrow's version of PMRT may have required less of the patients' attention during their chemotherapy and was, as a result, less efficacious than was this procedure in other studies in which patients did use imagery during the infusion (e.g., Lyles et al., 1982). There is one study that did not support the use of distraction: Cotanch and Strum (1985) reported that listening to audiotapes of music was not successful in reducing the aversiveness of chemotherapy. Perhaps the distractor used in this study was not sufficiently engaging; that is, listening to music may not have occupied completely the patients' cognitive capacity, which is a necessary characteristic of effective cognitive distractors (see McCaul \& Malott, 1984). In summary, attentional diversion or cognitive distraction may play an important role in reducing psychological side effects.

Enhanced perception of self-efficacy and mastery. In one way or another, all of the treatments discussed afford patients an active coping strategy (cf. Goldfried, 1971; Goldfried \& Trier, 1974) and may produce in patients an increased sense of selfefficacy or of perceived mastery (see Bandura, 1977). Morrow and Morrell's (1982) modified SD procedure, for example, has patients imagining themselves staying relaxed and calm in situations that formerly caused considerable anxiety. PMRT and hypnosis procedures show patients how to relax in the midst of a busy chemotherapy treatment room, seated in the treatment chair, with the tray of syringes at their side. Attentional diversion techniques illustrate how the patients can control their attention so as to virtually ignore and thereby render impotent the conditioned stimuli in the environment. The confidence developed when a person believes that the use of an intervention will allow control over a stressful situation may, in the chemotherapy context as in many other contexts, be an important ingredient of the treatment package.

It may be said that the data on health locus of control, a concept related to perceived mastery, do not support the enhanced self-efficacy explanation. For example, Morrow and Morrell (1982) found that reductions in anticipatory nausea and vomiting were not accompanied by corresponding changes in health locus of control. Also, we (Burish et al., 1984) have found that chemotherapy patients with a high external health locus of control orientation are more likely to benefit from a treatment intervention than are patients low on this dimension. Although our data appear to weaken the perceived mastery explanation (Burish et al., 1984), upon reflection, this may not be so: health locus of control measures a person's view of where the locus of control lies, not whether there is control or whether one desires or has control. Indeed, even if the control lies in a source external to one's self (e.g., in a videotape or a psychologist's suggestions), by availing oneself of that source of control, one could clearly come to believe that mastery can be achieved. Although the role of perceived mastery and self-efficacy is hypothetical at this point, it warrants continued empirical investigation.

\footnotetext{
${ }^{6}$ Systematic desensitization may be thought to involve cognitive participation only during training; because SD training has typically occurred outside of the chemotherapy context, it would appear that SD does not involve a distracting component during the actual chemotherapy infusion. Alternatively, however, SD may involve a distraction component during chemotherapy if patients are actively using the relaxation procedures that they learned during training as a way of managing discomfort, distress, or both resulting from venipuncture, the infusion, or other chemotherapy procedures. In this case, SD would appear to involve an active distraction component.
} 
Conclusion. Five different mechanisms have been proposed in order to explain the efficacy of psychological interventions for the reduction of conditioned and stress-related responses in cancer chemotherapy. At this stage, the comparative research needed to answer the question, "How do these treatments exert their impact?", is incomplete. Nonetheless, on the basis of the limited research that has addressed this question, either directly or indirectly, we conclude that it is unlikely that any single mechanism adequately accounts for the beneficial effects that have been observed in this context. Rather, we suggest that these different mechanisms should be viewed as cooperating and interacting to produce an effect rather than as competing hypotheses. A related interpretation is that the different mechanisms proposed herein reflect different levels of analysis in a biopsychosocial framework (cf. Engel, 1977; Schwartz, 1982).

\section{Clinical Issues}

In previous reviews of the literature (e.g., Burish \& Carey, 1984; Redd \& Andrykowski, 1982), several important clinical issues were discussed, including (a) choosing among the various interventions, (b) promoting maintenance of treatment gains, and (c) identifying individuals at risk for not profiting from psychological interventions and developing approaches to meet their special needs. These issues continue to be important, but in this article we discuss four additional issues that have emerged in recent years.

First, to date, most work concerned with nausea and vomiting in cancer patients has been either biomedical or psychosocial in nature. Many psychosocial researchers regard pharmacological (i.e., antiemetic) treatments as nuisance variables requiring methodological control. Similarly, biomedical researchers have neglected important psychosocial issues (Carey, Burish, \& Brenner, 1983). The time has come for biomedical and psychosocial research on nausea and vomiting to be integrative and complementary, with the goal being to develop the best possible treatment package. A psychological intervention that commences prior to the initiation of chemotherapy, combined with an effective drug protocol that balances antiemetic protection with toxic side effects, may be able to prevent or substantially reduce most nausea and vomiting associated with chemotherapy. Interdisciplinary (i.e., biopsychosocial; Engel, 1977; Schwartz, 1982) research of this nature is clearly desirable.

Second, in order for psychological interventions to be used widely in cancer clinics and hospitals throughout the country, a more favorable cost-effectiveness ratio is needed. Most cancer clinics do not use psychological interventions, even though they may be aware of their efficacy, because of the monetary costs and time involved (usually several hours per patient) or the lack of available and trained therapists. We recently completed a study to determine whether our PMRT and guided imagery intervention could be delivered as effectively by audiotapes or by trained paraprofessionals as by experienced psychologists (Carey \& Burish, 1987). Unfortunately, our data suggest that the experienced therapists were significantly more effective than the other service delivery techniques, which dampens our enthusiasm for these alternate approaches as cost-effective solu- tions. The modified SD procedure used by Morrow and Morrell (1982) requires perhaps the least amount of intervention time (about $2 \mathrm{hr}$ ), but outcome data are not available beyond two postintervention sessions. Distraction has the potential of being a cost-effective approach, although it may be necessary to insure that external distractors are always available to patients, at home and in the clinic. Clearly, low-cost delivery techniques are needed in order to make the current technology available to the majority of chemotherapy patients who could benefit from it.

Third, in some settings and for some types of chemotherapy treatment protocols, nausea and vomiting have become less problematic in recent years. For example, Stefanek, Sheidler, and Fetting (1988) compared the prevalence and severity rates of anticipatory symptoms reported by adult patients in their clinic in 1987 with those of approximately 5 years earlier. In general, they found that while the prevalence rates were similar, the severity ratings were lower; that is, there was a significant decrease in severity from the first to the second sampling, with the more recent ratings indicating that anticipatory nausea and vomiting were no longer "a significant clinical problem" for patients receiving parenteral chemotherapy. We have also noticed a decline in the severity of these side effects, as well as a decreased prevalence, in adult patients seen in our clinic (Carey $\&$ Burish, 1987). Moreover, we anticipate that this trend may continue, at least in adults, largely because of the development of antiemetic drugs that are less toxic and more effective and because of the increased availability of these medications beyond major medical centers. If we assume that this trend is occurring and does continue, will this mean that in the future there will be less need for psychological interventions with chemotherapy patients? We believe the answer is no. But these data and observations, and reports of the side effects of newer forms of cancer treatments (e.g., interleukin-2), do suggest that the focus of the psychological interventions may need to change. As this review has shown, most of the psychological research with chemotherapy patients has focused on nausea and vomiting as the only or the primary outcome measures. However, psychological interventions can have a positive effect on a number of other symptoms that chemotherapy patients experience, including negative emotional states (Lyles et al., 1982), reduced food intake (Campbell, Dixon, Sanderford, \& Denicola, 1984), and pain (Spiegel, 1985). Future researchers might do well to broaden both the symptoms that are targeted and the outcome measures that are assessed. We suspect that such an approach will ultimately provide even stronger support for the use of psychological interventions with cancer patients.

Finally, research on the treatment of psychological responses to cancer chemotherapy has progressed to a point at which oneshot, noncontrolled studies will usually contribute little, empirically or heuristically, to the area. Advances will depend increasingly upon controlled studies that build upon prior findings. Comparative studies, and studies using a dismantling design in order to clarify treatment mechanisms, hold much promise. And, as indicated earlier, continued research on the etiology of conditioned and stress-related responses to cancer chemotherapy is warranted.

\section{Conclusion}

On the basis of the data reviewed, it can be concluded that the psychological symptoms that result from cancer chemotherapy 
appear to be the product of both associative learning and the stress associated with chemotherapy. Moreover, these side effects can, in many instances, be prevented or ameliorated with psychological techniques. This conclusion is based on research conducted in a variety of clinics, on children and adults, by independent research teams, using poorly controlled as well as well-controlled methodological designs. Overall, therefore, these findings can be considered robust.

Although considerable knowledge has been generated in a short period of time, and although the rate of publications continues to increase, we believe that research on the psychological treatment of the side effects of cancer chemotherapy is at a critical point in its development. The use of progressively less toxic and more effective antiemetic drugs, the increased emphasis on cost-effectiveness, and the methodological and scientific evolution of the field will demand changes in the strategies and approaches used by psychosocial investigators. For example, a focus on why some people do not benefit from psychological treatments might prove useful theoretically and clinically, as might more integrative, comprehensive treatment packages that include pharmacological components and that attempt to do more than reduce anticipatory nausea and vomiting. Such studies will help to insure that research on the treatment of psychological side effects of cancer chemotherapy continues to make significant theoretical and clinical advances.

\section{References}

Ader, R. (1981). Psychoneuroimmunology: Orlando, FL: Academic Press.

Ader, R., \& Cohen, N. (1985). CNS-immune system interactions: Conditioning phenomena. Behavioral and Brain Sciences, 8, 379-394.

Andrykowski, M. A., Jacobsen, P. B., Marks, E., Gorfinkle, K., Hakes, T., Kaufman, R. J., Currie, V. E., Holland, J. C., \& Redd, W. H. (in press). Prevalence, predictors, and course of anticipatory nausea in women receiving adjuvant chemotherapy for breast cancer. Cancer.

Andrykowski, M. A., \& Redd, W. H. (1987). Longitudinal analysis of the development of anticipatory nausea. Journal of Consulting and Clinical Psychology, 55, 36-41.

Andrykowski, M. A., Redd, W. H., \& Hatfield, A. K. (1985). Development of anticipatory nausea: A prospective analysis. Journal of Consulting and Clinical Psychology, 53, 447-454.

Bandura, A. (1977). Self-efficacy: Toward a unifying theory of behavioral change. Psychological Review, 85, 191-215.

Benson, H. (1975). The relaxation response. New York: Avon.

Bernstein, D. A., \& Borkovec, T. D. (1973). Progressive relaxation training: A manual for the helping professions. Champaign, IL: Research Press.

Bernstein, I. L. (1978). Learned taste aversions in children receiving chemotherapy. Science, 200, 1302-1303.

Bernstein, I. L., \& Borson, S. (1986). Learned food aversion: A component of anorexia syndromes. Psychological Review, 93, 462-472.

Bernstein, I. L., \& Webster, M. M. (1980). Learned taste aversions in humans. Physiology and Behavior, 25, 363-366.

Bernstein, I. L., \& Webster, M. M. (1985). Learned food aversions: A consequence of cancer chemotherapy. In T. G. Burish, S. M. Levy, \& B. E. Meyerowitz (Eds.), Cancer, nutrition, and eating behavior: $A$ biobehavioral perspective (pp. 103-116). Hillsdale, N3: Erlbaum.

Borison, H. L., \& McCarthy, L. E. (1983). Neuropharmacologic mechanisms of emesis. In J. Laszlo (Ed.), Antiemetics and cancer chemotherapy (pp. 6-20). Baltimore, MD: Williams \& Wilkins.
Borkovec, T. D., \& Sides, J. K. (1979). Critical procedural variables related to the physiological effects of progressive relaxation: A review. Behaviour Research and Therapy, 17, 119-126.

Burish, T. G., \& Carey, M. P. (1984). Conditioned responses to cancer chemotherapy: Etiology and treatment. In B. H. Fox \& B. H. Newberry (Eds.), Impact of psychoendocrine systems in cancer immunity (pp. 147-178). Toronto: Hogrefe.

Burish, T. G., \& Carey, M. P. (1986). Conditioned aversive responses in cancer chemotherapy patients: Theoretical and developmental analysis. Journal of Consulting and Clinical Psychology, 54, 593-600.

Burish, T. G., Carey, M. P., Krozely, M. G., \& Greco, F. A. (1987). Conditioned nausea and vomiting induced by cancer chemotherapy: Prevention through behavioral treatment. Journal of Consulting and Clinical Psychology, 55, 42-48.

Burish, T. G., Carey, M. P., Wallston, K. A., Stein, M. J., Jamison, R. N., \& Lyles, J. N. (1984). Health locus of control and chronic disease: An external orientation may be advantageous. Journal of Social and Clinical Psychology, 2, 326-332.

Burish, T. G., \& Lyles, J. N. (1979). Effectiveness of relaxation training in reducing the aversiveness of chemotherapy in the treatment of cancer. Journal of Behavior Therapy and Experimental Psychiatry, 10, 357-361.

Burish, T. G., \& Lyles, J. N. (1981). Effectiveness of relaxation training in reducing adverse reactions to cancer chemotherapy. Journal of Behavioral Medicine, 4, 65-78.

Burish, T. G., Shartner, C. D., \& Lyles, J. N. (1981). Effectiveness of multiple-site EMG biofeedback and relaxation in reducing the aversiveness of cancer chemotherapy. Biofeedback and Self-Regulation, 6, 523-535.

Campbell, D. F., Dixon, J. F., Sanderford, L. D., \& Denicola, M. D. (1984). Relaxation: Its effect on the nutritional status and performances status of clients with cancer. Journal of the American Dietetic Association, 84, 201-204.

Carey, M. P., \& Burish, T. G. (1985). Anxiety as a predictor of behavioral therapy outcome for cancer chemotherapy patients. Journal of Consulting and Clinical Psychology, 53, 860-865.

Carey, M. P., \& Burish, T. G. (1987). Providing relaxation training to cancer chemotherapy patients: A comparison of three methods. Journal of Consulting and Clinical Psychology, 55, 732-737.

Carey, M. P., Burish, T. G., \& Brenner, D. E. (1983). Delta-9-tetrahydrocannabinol in cancer chemotherapy: Research problems and issues. Annals of Internal Medicine, 99, 106-114.

Chang, J. C. (1981). Nausea and vomiting in cancer patients: An expression of psychological mechanisms? Psychosomatics, 22, 707-709.

Cohn, K. H. (1982). Chemotherapy from an insider's perspective. Lancet, 1, 1006-1009.

Collins, K. H., \& Tatum, A. L. (1925). A conditioned salivary reflex established by chronic morphine poisoning. American Journal of Physiology, 74, 14-15.

Cotanch, P. (1983). Relaxation training for control of nausea and vomiting in patients receiving chemotherapy. Cancer Nursing, 6, 277283.

Cotanch, P., Hockenberry, M., \& Herman, S. (1985). Self-hypnosis antiemetic therapy in children receiving chemotherapy. Oncology Nursing Forum, 12, 41-46.

Cotanch, P., \& Strum, S. (1985). Progressive muscle relaxation as antiemetic therapy for cancer patients: $A$ controlled study. Unpublished manuscript, Duke University, Durham, NC.

Dahlquist, L. M., Gil, K. M., Armstrong, F. D., Ginsberg, A., \& Jones, B. (1985). Behavioral management of children's distress during chemotherapy. Journal of Behavior Therapy and Experimental Psychiatry, 16, 325-329.

Dempster, C. R., Balson, P., \& Whalen, B. T. (1976). Supportive hypno- 
therapy during the radical treatment of malignancies. International Journal of Clinical and Experimental Hypnosis, 24, 1-9.

Dolgin, M. J., Katz, E. R., McGinty, K., \& Siegel, S. E. (1985). Anticipatory nausea and vomiting in pediatric cancer patients. Pediatrics, $75,547-552$.

Ellenberg, L., Kellerman, J., Dash, J., Higgins, G., \& Zeltzer, L. (1980). Use of hypnosis for multiple symptoms in an adolescent girl with leukemia. Journal of Adolescent Health Care, 1, 132-136.

Engel, G. L. (1977). The need for a new medical model: A challenge for biomedicine. Science, 196, 129-136.

Fetting, J. H., Sheidler, V. R., Stefanek, M. E., \& Enterline, J. P. (1987). Clonidine for anticipatory nausea and vomiting: A pilot study examining dose-toxicity relationships and potential for further study. Cancer Treatment Reports, 71, 409-410.

Frank, J. D. (1973). Persuasion and healing (2nd ed.). Baltimore, MD: Johns Hopkins University.

Garcia y Robertson, R., \& Garcia, J. (1985). X-rays and learned taste aversions: Historical and psychological ramifications. In T. G. Burish, S. M. Levy, \& B. E. Meyerowitz (Eds.), Cancer, nutrition, and eating behavior: A biobehavioral perspective (pp. 11-41). Hillsdale, NJ: Erlbaum.

Goldfried, M. R. (1971). Systematic desensitization as training in selfcontrol. Journal of Consulting and Clinical Psychology, 37, 228-234.

Goldfried, M. R., \& Trier, C. S. (1974). Effectiveness of relaxation as an active coping skill. Journal of Abnormal Psychology, 83, 348-355.

Greene, P. G., Seime, R. J., \& Smith, M. E. (1985). Distraction and relaxation training in the treatment of anticipatory nausea and vomiting: A single subject intervention. Manuscript submitted for publication.

Hailey, B. J., \& White, J. G. (1983). Systematic desensitization for anticipatory nausea associated with chemotherapy. Psychosomatic, 24, 289-291.

Hamberger, L. K. (1982). Reduction of generalized aversive responding in a posttreatment cancer patient: Relaxation as an active coping skill. Journal of Behavior Therapy and Experimental Psychiatry, 13, 229233.

Hendler, C. S., \& Redd, W. H. (1986). Fear of hypnosis: The role of labeling in patients' acceptance of behavioral interventions. Behavior Therapy, 17, 2-13.

Hoffman, J. W., Benson, H., Arns, P. A., Stainbrook, G. L., Landsberg, L., Young, J. B., \& Gill, A. (1982). Reduced sympathetic nervous system responsivity associated with the relaxation response. Science, 215, 190-192.

Hoffman, M. L. (1982-1983). Hypnotic desensitization for the management of anticipatory emesis in chemotherapy. American Journal of Clinical Hypnosis, 25, 173-176.

Ingle, R. J., Burish, T. G., \& Wallston, K. A. (1984). Conditionability of cancer chemotherapy patients. Oncology Nursing Forum, 11, 97102.

Jacobsen, P. B., Andrykowski, M. A., Redd, W. H., Die-Trill, M., Hakes, T. B., Kaufman, R. J., Currie, V. E., \& Holland, J. C. (1988). Nonpharmacologic factors in the development of posttreatment nausea with adjuvant chemotherapy for breast cancer. Cancer, 61,379 385.

Jacobson, E. (1938). Progressive relaxation. Chicago, IL: University of Chicago.

Kazdin, A. E., \& Wilcoxon, L. A. (1976). Systematic desensitization and nonspecific treatment effects: A methodological evaluation. Psychological Bulletin, 83, 729-758.

Kolko, D. J., \& Rickard-Figueroa, J. L. (1985). Effects of video games on the adverse corollaries of chemotherapy in pediatric oncology patients: A single-case analysis. Journal of Consulting and Clinical Psychology, 53, 223-228.
Kutz, I., Borysenko, J. Z., Come, S. E., \& Benson, H. (1980). Paradoxi$\mathrm{cal}$ emetic response to antiemetic treatment in cancer patients. New England Sournal of Medicine, 303, 1480.

LaBaw, W., Holton, C., Tewell, K., \& Eccles, D. (1975). The use of selfhypnosis by children with cancer. American Journal of Clinical Hypnosis, 17, 233-238.

Lader, M. (1984). Pharmacological methods. In R. L. Woolfolk \& P. M. Lehrer (Eds.), Principles and practice of stress management (pp. 306333). New York: Guilford.

Lang, P. J. (1969). The mechanics of desensitization and the laboratory study of fear. In C. M. Franks (Ed.), Behavior therapy: Appraisal and status. New York: MoGraw-Hill.

Laszlo, J. (1983). Antiemetics and cancer chemotherapy. Baltimore, MD: Williams \& Wilkins.

Laszlo, J., \& Lucas, V. S. (1981). Emesis as a critical problem in chemotherapy. New England Journal of Medicine, 305, 948-949.

Lazarus, R. S. (1966). Psychological stress and the coping process. New York: McGraw-Hill.

Lazarus, R. S., \& Folkman, S. (1984). Stress, appraisal, and coping. New York: Springer.

LeBaron, S., \& Zeltzer, L. K. (1984). Behavioral intervention for reducing chemotherapy-related nausea and vomiting in adolescents with cancer. Journal of Adolescent Health Care, 5, 178-182.

Lehrer, P. M., \& Woolfolk, R. L. (1984). Are stress reduction techniques interchangeable, or do they have specific effects?: A review of the comparative empirical literature. In R. L. Woolfolk \& P. M. Lehrer(Eds.), Principles and practice of stress management (pp. 404-477). New York: Guilford.

Leventhal, H., Easterling, D. V., Nerenz, D. R., \& Love, R. R. (1988). The role of motion sickness in predicting anticipatory nausea. Journal of Behavioral Medicine, 11, 117-130.

Lyles, J. N., Burish, T. G., Krozely, M. G., \& Oldham, R. K. (1982). Efficacy of relaxation training and guided imagery in reducing the aversiveness of cancer chemotherapy. Journal of Consulting and Clinical Psychology, 50, 509-524.

Masters, J. C., Burish, T. G., Hollon, S. D., \& Rimm, D. C. (1987). Behavior therapy (3rd ed.). New York: Harcourt Brace Jovanovich.

McCaul, K. D., \& Malott, J. M. (1984). Distraction and coping with pain. Psychological Bulletin, 95, 516-533.

McGlynn, F. D., Mealiea, W. L., Jr., \& Landau, D. L. (1981). The current status of systematic desensitization. Clinical Psychology Review, 1, 149-179.

Moore, K., \& Altmaier, E. M. (1981). Stress inoculation training with cancer patients. Cancer Nursing, 4, 389-393.

Morrow, G. R. (1982). Prevalence and correlates of anticipatory nausea and vomiting in chemotherapy patients. Journal of the National Cancer Institute, 68, 484-488.

Morrow, G. R. (1985). The effect of a susceptibility to motion sickness on the side effects of cancer chemotherapy. Cancer, 55, 2766-2770.

Morrow, G. R. (1986). Effect of the cognitive hierarchy in the systematic desensitization treatment of anticipatory nausea in cancer patients: A component comparison with relaxation only, counseling and no treatment. Cognitive Therapy and Research, 10, 421-446.

Morrow, G. R., Arseneau, J. C., Asbury, R. F., Bennett, J. M., \& Boros, L. (1982). Anticipatory nausea and vomiting with chemotherapy. New England Journal of Medicine, 306, 431-432.

Morrow, G. R., \& Morrell, C. (1982). Behavioral treatment for the anticipatory nausea and vomiting induced by cancer chemotherapy. New England Journal of Medicine, 307, 1476-1480.

Nerenz, D. R., Leventhal, H, Easterling, D. V., \& Love, R. R. (1986). Anxiety and drug taste as predictors of anticipatory nausea in cancer chemotherapy. Journal of Clinical Oncology, 4, 224-233.

Nerenz, D. R., Leventhal, H., \& Love, R. R. (1982). Factors contribut- 
ing to emotional distress during cancer chemotherapy. Cancer, 50 , 1020-1027.

Nerenz, D. R., Leventhal, H., Love, R. R., \& Ringler, K. E. (1984). Psychological aspects of cancer chemotherapy. International Journal of Applied Psychology, 33, 521-529.

Oberst, M. T. (1978), Priorities in cancer nursing research. Cancer Nursing, 1, 281.

Pavlov, I. P. (1927). Conditioned reflexes: An investigation of physiological activity of the cerebral cortex (Lecture III). Oxford, England: Oxford University Press.

Redd, W. H. (1985/1986). Use of behavioral methods to control the aversive effects of chemotherapy. Journal of Psychosocial Oncology, $3,17-22$.

Redd, W. H., Andresen, G. V., \& Minagawa, R. Y. (1982). Hypnotic control of anticipatory emesis in patients receiving cancer chemotherapy. Journal of Consulting and Clinical Psychology, 50, 14-19.

Redd, W. H., \& Andrykowski, M. A. (1982). Behavioral intervention in cancer treatment: Controlling aversion reactions to chemotherapy. Journal of Consulting and Clinical Psychology, 50, 1018-1029.

Redd, W. H., Jacobsen, P. B., Die-Trill, M., Dermatis, H., McEvoy, M., \& Holland, J. C. (1987). Cognitive/attentional distraction in the control of conditioned nausea in pediatric cancer patients receiving chemotherapy. Journal of Consulting and Clinical Psychology, 55, 391-395.

Schwartz, G. E. (1982). Testing the biopsychosocial model: The ultimate challenge facing behavioral medicine. Journal of Consulting and Clinical Psychology, 50, 1040-1053.

Scott, D. W., Donahue, D. C., Mastrovito, R. C., \& Hakes, T. B. (1983). The antiemetic effect of clinical relaxation: Report of an exploratory pilot study. Joumal of Psychosocial Oncology, 1, 71-84.

Selye, H. (1976). The stress of life (rev. ed.). New York: McGraw-Hill.

Shartner, C. D., Burish, T. G., \& Carey, M. P. (1985). Effectiveness of biofeedback with progressive muscle relaxation training in reducing the aversiveness of cancer chemotherapy: A preliminary report. Japanese Journal of Biofeedback Research, 12, 33-40.

Siegel, L. J., \& Longo, D. L. (1981). The control of chemotherapy-induced emesis. Annals of Internal Medicine, 95, 352-359.

Siegel, S. (1979). The role of conditioning in drug tolerance and addiction. In J. D. Keehn (Ed.), Psychopathology in animals: Research and clinical applications (pp. 143-168). Orlando, FL: Academic Press.

Silverberg, E., \& Lubera, J. (1986). Cancer statistics, 1986. CA-A Journal for Clinicians, 36, 9-25.

Smith, J. C., Blumsack, J. T., \& Bilek, F. S. (1985). Radiation-induced taste aversions in rats and humans. In T. G. Burish, S. M. Levy, \& B. E. Meyerowitz (Eds.), Cancer nutrition, and eating behavior: $A$ biobehavioral perspective (pp. 77-101). Hillsdale, NJ: Erlbaum.
Spence, K. W. (1958). A theory of emotionally based drive (D) and its relation to performance in simple learning situations. American Psychologist, 13, 131-141.

Spiegel, D. (1985). The use of hypnosis in controlling cancer pain. $C A-$ A Cancer Journal for Clinicians, 35, 221-231.

Stefanek, M. E., Sheidler, V. R., \& Fetting, J. H. (1988). Anticipatory nausea and vomiting: Does it remain a significant clinical problem? Unpublished manuscript, Johns Hopkins University, Baltimore, MD.

Thoresen, C. E., \& Mahoney, M. J. (1974). Behavioral self-control. New York: Holt, Rinehart \& Winston.

Turk, D. C., Meichenbaum, D., \& Genest, M. (1983). Pain and behavioral medicine: A cognitive-behavioral perspective. New York: Guilford.

van Komen, R. W., \& Redd, W. H. (1985). Personality factors associated with anticipatory nausea/vomiting in patients receiving cancer chemotherapy. Health Psychology, 4, 189-202.

Wadden, T. A., \& Anderton, C. H. (1982). The clinical use of hypnosis. Psychological Bulletin, 91, 215-243.

West, B. L., \& Piccionne, C. (1982). Cognitive-behavioral techniques in treating anorexia and depression in a cancer patient. The Behavior Therapist, 5, 115-117.

Wilcox, P. M., Fetting, J. H., Nettesheim, K. M., \& Abeloff, M. D. (1982). Anticipatory vomiting in women receiving cyclophosphamide, methotrexate, and 5-FU (CMF) adjuvant chemotherapy for breast carcinoma. Cancer Treatment Reports, 66, 1601-1604.

Wolpe, J. (1958). Psychotherapy by reciprocal inhibition. Stanford, CA: Stanford University.

Zeltzer, L. K., Kellerman, J., Ellenberg, L., \& Dash, J. (1983). Hypnosis for reduction of vomiting associated with chemotherapy and disease in adolescents with cancer. Journal of Adolescent Health Care, 4, 7784.

Zeltzer, L. K., \& LeBaron, S. (1986). Assessment of acute pain and anxiety and chemotherapy related nausea and vomiting in children and adolescents. Hospice Journal, 2(3), 75-98.

Zeltzer, L. K., LeBaron, S., \& Zeltzer, P. (1984a). Paradoxical effects of prophylactic phenothiazine antiemetics in children receiving chemotherapy. Journal of Clinical Oncology, 2, 930-936.

Zeltzer, L. K., LeBaron, S., \& Zeltzer, P. (1984b). The effectiveness of behavioral intervention for reducing nausea and vomiting in children receiving chemotherapy. Journal of Clinical Oncology, 2, 683-690.

Received December 15, 1986

Revision received March 14, 1988 Accepted March 22, 1988 